\title{
REVIEW ARTICLE OPEN Bench-to-bedside strategies for osteoporotic fracture: From osteoimmunology to mechanosensation
}

\author{
Yong Xie ${ }^{1}$, Licheng Zhang ${ }^{1}$, Qi Xiong ${ }^{2}$, Yanpan $\mathrm{Gao}^{3}$, Wei Ge ${ }^{3}$ and Peifu Tang ${ }^{1}$
}

\begin{abstract}
Osteoporosis is characterized by a decrease in bone mass and strength, rendering people prone to osteoporotic fractures caused by low-energy forces. The primary treatment strategy for osteoporotic fractures is surgery; however, the compromised and comminuted bones in osteoporotic fracture sites are not conducive to optimum reduction and rigid fixation. In addition, these patients always exhibit accompanying aging-related disorders, including high inflammatory status, decreased mechanical loading and abnormal skeletal metabolism, which are disadvantages for fracture healing around sites that have undergone orthopedic procedures. Since the incidence of osteoporosis is expected to increase worldwide, orthopedic surgeons should pay more attention to comprehensive strategies for improving the poor prognosis of osteoporotic fractures. Herein, we highlight the molecular basis of osteoimmunology and bone mechanosensation in different healing phases of elderly osteoporotic fractures, guiding perioperative management to alleviate the unfavorable effects of insufficient mechanical loading, high inflammatory levels and pathogen infection. The well-informed pharmacologic and surgical intervention, including treatment with anti-inflammatory drugs and sufficient application of antibiotics, as well as bench-to-bedside strategies for bone augmentation and hardware selection, should be made according to a comprehensive understanding of bone biomechanical properties in addition to the remodeling status of osteoporotic bones, which is necessary for creating proper biological and mechanical environments for bone union and remodeling. Multidisciplinary collaboration will facilitate the improvement of overall osteoporotic care and reduction of secondary fracture incidence.
\end{abstract}

Bone Research (2019)7:25; https://doi.org/10.1038/s41413-019-0066-7

\section{INTRODUCTION}

The major characteristic of osteoporosis is a decrease in bone mass and quality, ${ }^{1}$ rendering people prone to osteoporotic fracture (fragility fracture) caused by low-energy trauma. ${ }^{2}$ Osteoporosis is a prevailing skeletal disease of the elderly; nearly 200 million osteoporotic patients are diagnosed annually, and almost 9 million osteoporotic fractures occur worldwide. ${ }^{3}$ Surgery is the primary treatment strategy for osteoporotic fracture; however, poor prognoses are presented due to the combination of biological and surgical factors. ${ }^{4}$ The common sites of osteoporotic bones are usually compromised and comminuted, which makes it hard to achieve an optimum reduction and stable fixation. ${ }^{3,5}$ Osteoporotic fractures occur mostly in elderly patients, who exhibit underlying, unfavorable systemic conditions that are prone to complications. ${ }^{6}$ The abnormal remodeling status of bone with osteoporosis would deteriorate after bed braking, which poses a disadvantage with respect to fracture healing and bone callus strength; furthermore, the refracture risk following surgery increases significantly. ${ }^{7}$ In terms of the complexity of treatment and poor prognosis, the annual facility-related hospital cost of osteoporotic fractures is the highest (up to $\$ 5.1$ billion), followed by that of myocardial infarction and stroke. ${ }^{8}$

Although the results of the clinical studies remain controversial, the majority have demonstrated that decreased callus area
(20\%-40\%) and bone mineral density (BMD) occur in the fracture sites of elderly osteoporotic patients ${ }^{4}$. Studies have indicated that the delayed or nonunion of osteoporotic fractures is implicated in the scarce capacity of bone regeneration with aging., ${ }^{9,10}$ Additionally, the bone properties of such patients are quite different from those of normal individuals and are manifested in the decrease of bone mechanics and mechanosensation, as well as the abnormal bone metabolism caused by immune disorders. ${ }^{11}$ To improve the current unsatisfactory status of osteoporotic fracture treatment, we must first gain an in-depth understanding of the mechanism of fracture healing in elderly patients with osteoporosis. Herein, we highlight the pivotal roles of mechanical loading and osteoimmunology in aging-related osteoporotic fractures, guiding the intervention in osteoporotic fracture patients combined with an optimal treatment strategy for improving the overall standard of care and reducing the incidence of secondary fracture.

\section{STATIC AND DYNAMIC CHANGES IN OSTEOPOROTIC BONE} Bone is a unique tissue due to its elasticity and strength that permits deformation under a certain level of loading stress before failing. ${ }^{12}$ The strength of bone is mainly dependent on the distribution and density of the inorganic matrix

\footnotetext{
${ }^{1}$ Department of Orthopedics, Chinese PLA General Hospital, Beijing, China; ${ }^{2}$ Department of Oncology, Chinese PLA General Hospital, Beijing, China and ${ }^{3}$ State Key Laboratory of Medical Molecular Biology and Department of Immunology, Institute of Basic Medical Sciences, Chinese Academy of Medical Sciences, Beijing, China Correspondence: Wei Ge (wei.ge@chem.ox.ac.uk) or Peifu Tang (pftang301@163.com)

These authors contributed equally: Yong Xie, Licheng Zhang, Qi Xiong
}

Received: 1 November 2018 Revised: 20 June 2019 Accepted: 21 June 2019

Published online: 15 August 2019 

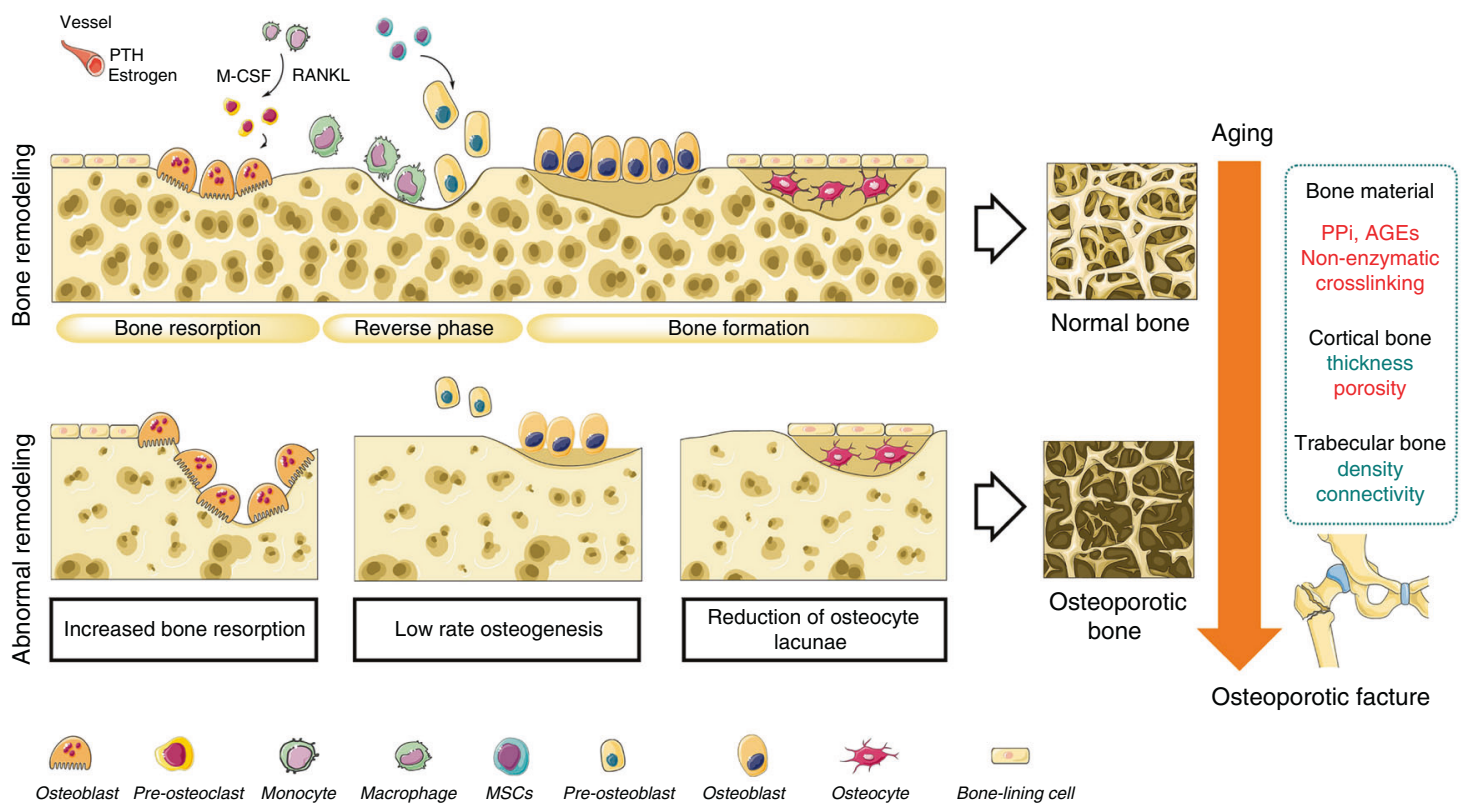

Fig. 1 Static and dynamic changes in osteoporotic bone. An osteoporotic fracture is the macroscopic result of microstructural alterations that change the response of bone to the applied load. The aging process in osteoporotic bone would lead to overaccumulation of PPi, AGEs, and nonenzymatic crosslinking of collagen, which disturb the normal organization of bone material. With the increase of bone resorption and low rate osteogenesis, the osteocyte lacunae reduction leads to decreased trabecular thickness and more porous cortical bone. PTH parathyroid hormone, M-CSF macrophage colony-stimulating factor, RANKL receptor activator of nuclear factor kappa-B ligand, PPi inorganic pyrophosphate, AGEs advanced glycation end-products, MSCs mesenchymal stem cells. "Red" refers to upregulation; "Green" refers to downregulation

mineralization. ${ }^{13}$ Cortical bone consisting of dense and wellorganized lamellae has higher strength but a lower capacity to withstand a load that exceeds the elastic deformation range compared with that of trabecular bone, which is composed of unparallel lamellar units with variable porosity $(50 \%-90 \%) .{ }^{14}$ The mechanical competence of cancellous bone is based largely on the BMD, while the stiffness of cortical bone is highly dependent on its porosity. ${ }^{3,15}$ In contrast to calcified matrix mineralization, the organic matrix (e.g., collagen and noncollagenous proteins) is thought to control bone ductility and its capacity to withstand an impact without cracking. ${ }^{16}$ A large proportion (90\%) of the organic matrix is composed of type I collagen, which undergoes numerous posttranslational modifications. ${ }^{17}$ Among them, enzymatic modifications positively affect the biomechanical stability of bone, while nonenzymatic crosslinking is associated with a deterioration in these properties. ${ }^{16}$ Noncollagenous proteins, including osteopontin (OPN) and osteocalcin (OCN), account for $10 \%$ of the organic matrix and limit crack energy through the control of hydroxyapatite size and orientation. ${ }^{18}$ Whereas bone material properties provide only a static snapshot of bone quality, the abilities of self-regeneration and remodeling provide a dynamic profile of bone health. ${ }^{19}$ The cortical and trabecular bone both undergo lifelong remodeling coupled with bone resorption, which is mediated by osteoclasts following osteoblastic bone formation. ${ }^{20}$ Osteoclasts are of hematopoietic stem cell (HSC) origin and share precursors with macrophages. ${ }^{21}$ In the presence of macrophage colony-stimulating factor (M-CSF), osteoclast precursors differentiate to preosteoclasts by the binding of receptor activator of nuclear factor kappa-B ligand (RANKL) to its cognate receptor, receptor activator of nuclear factor kappa-B (RANK). These mononuclear preosteoclasts then fuse to form multinuclear bone-resorbing osteoclasts. ${ }^{21}$ In contrast, osteoblasts are derived from mesenchymal stem cells (MSCs), ${ }^{22}$ and osteoblastic bone formation is separated from resorption by a reversal phase for several weeks. ${ }^{23}$ Mature osteoblasts then differentiate into osteocytes, which reside in small lacunae inside the calcified bone matrix. ${ }^{24}$ The long dendritic extensions of osteocytes together with the cell bodies form the lacuno-canalicular network (LCN), which allows direct signal transduction. The speed of mineral accumulation in the bone remodeling cycle is also affected by numerous endocrine factors, such as parathyroid hormone (PTH) and estrogen, which are supplied by the bone vascular systems. ${ }^{25,26}$ However, the normal regulation of bone remodeling could be interrupted as a consequence of skeletal senescence, ${ }^{27,28}$ which impact the integrity and biomechanical properties of both cortical and cancellous bones. ${ }^{29}$ The abnormal bone remodeling shifts toward bone resorption, which is either due to excessive activation of osteoclasts or to a low capacity of bone regeneration. ${ }^{30}$ In addition, age-related loss of proteostasis and increased levels of oxidants result in the overaccumulation of inorganic pyrophosphate (PPi) or advanced glycation endproducts (AGEs). During the development of osteoporosis, osteocyte numbers per unit of bone area are gradually reduced, ${ }^{31}$ resulting in decreased trabecular thickness and more intracortical porosity. ${ }^{32}$ These considerable changes in the matrix composition and structure cause deterioration of bone quality and compromise its resistance to mechanical loading. ${ }^{33}$ Thus, osteoporotic fractures are the macroscopic result of microstructural alterations that increase the susceptibility of bone to the applied load ${ }^{34}$ (Fig. 1).

\section{OSTEOIMMUNOLOGY IN HEMATOMA AND INFLAMMATORY PHASES}

Secondary fracture healing occurs after a fracture without rigid fixation. Under the influence of active loading, an external callus is initiated to bridge the fracture gap ${ }^{35}$ in a three-stage process consisting of inflammation, repair, and remodeling. ${ }^{36}$ The first two of these partially overlapping phases restore bone structure and 
continuity over a period of 3 months to allow full weight bearing. The last phase involves gradual remodeling of bone to withstand the usual strains of daily life. ${ }^{37}$ In contrast, primary fracture healing without formation of a periosteal callus usually requires direct contact of compact bone or rigid surgical intervention that makes the fracture gap $<200 \mu \mathrm{m}$. However, elderly osteoporotic bones, such as metaphyseal sites, which are highly susceptible to bone degradation, make it difficult to maintain anatomical reduction and rigid fixation using traditional screws due to inadequate insertional torque. ${ }^{38}$ In this situation, the healing process will be more like indirect bony union with the response of loading and inflammation, forming a periosteal callus bridging the fracture gap. The specific osteoimmunology and mechanosensation status of patients with osteoporotic fractures affect these healing phases in different manners. ${ }^{39}$

Bone fracture induces immediate inflammation and bleeding around bone extremities and within the medulla, where a template is formed for callus formation, called a hematoma. ${ }^{40}$ Around the hematoma sites, inflammatory cells, such as macrophages/monocytes or $\mathrm{B} / \mathrm{T}$ cells, are activated to release inflammatory cytokines, including tumor necrosis factor alpha (TNF-a), interleukin-1 (IL-1), and interleukin-6 (IL-6) into the systemic circulation. ${ }^{41}$ These cytokines are responsible for the initiation of immune and inflammatory responses, ${ }^{42}$ including enhancement of blood flow and vessel permeability, as well as the recruitment of immune cells for pathogen clearance. ${ }^{43}$ The limited inflammatory response is required to initiate the repair cascade and mobilize all the required factors involved in the early bridging of the fracture gap, especially in indirect bony unions without rigid fixation. ${ }^{44}$ The interactions between the skeletal system and immune function, comprising osteoimmunology, in osteoporotic fractures are altered with age. ${ }^{45}$ It has been reported that an ageassociated decline in the absolute numbers of human $B$ cell precursors in bone marrow ${ }^{46}$ leads to a significant decrease in the number of mature human $B$ cells. ${ }^{47,48}$ Compared with young adults, the B cell repertoire is less diverse in elderly individuals. ${ }^{49}$ As to T cells, studies exhibit reductions of proliferation and helper function in CD4+ T cells that recruit neutrophils and macrophages to infected sites of elderly individuals. ${ }^{50}$ Consistent with this finding, the impaired neutrophi ${ }^{51} /$ monocytes $^{52}$-mediated phagocytosis also showed an age-dependent reduction. ${ }^{53}$ In contrast, the expression of Toll-like receptors (TLRs), a group of pattern recognition receptors (PRRs) that trigger pro-inflammatory responses, ${ }^{54}$ is increased in monocytes and dendritic cells in elderly people, accompanied by increased production of IL-1 and TNF-a. ${ }^{55}$ In vitro and in vivo studies have shown that persistent tumor necrosis factor (TNF) expression impairs cell-mediated immune responses and Th2 differentiation from naïve T cells. ${ }^{56-58}$ Moreover, constant stimulation by TNF-a elevates the threshold for $T$ cell activation via the T-cell receptor (TCR), attenuating $T$ cell responses to antigen ${ }^{59}$ and negatively affecting angiogenesis during fracture healing. ${ }^{60}$ Thus, the early immune responses and pathogen clearance of aged patients with osteoporotic fractures would be impaired or delayed due to the insufficient acquired immunity and dysfunction of the innate immune system. ${ }^{61}$ Furthermore, pathogen infections induce host inflammation and contribute to local bone loss. The most frequent pathogen identified in bone infection is Staphylococcus. ${ }^{62}$ Staphylococcus aureus protein $A$ induces the production of inflammatory cytokines, such as TNF-a, ${ }^{63}$ IL-6, interleukin-1 alpha (IL-1a), ${ }^{64}$ interleukin-1 beta (IL-1 $\beta),{ }^{64}$ and neutrophil-attracting chemokines in local tissues. On the one hand, short-term $(24 \mathrm{~h})$ upregulated cytokines, such as TNF-a are essential for local recruitment of neutrophils, ${ }^{41}$ macrophages, and $T$ cells for pathogen clearance. ${ }^{65,66}$ However, the long-term presence of these cytokines, especially TNF-a, IL-1, and IL-6, activates CD4+ T cells, promoting RANKL expression by osteoblasts ${ }^{67}$ and synergizing directly with RANK to amplify osteoclastogenesis ${ }^{68}$ and bone resorption. ${ }^{69}$
In general, high levels of pro-inflammatory cytokines, either in the circulation or local tissues, are found in the aged population. ${ }^{70}$ Serum IL-1, IL-6, and/or TNF-a levels have been shown to be upregulated in elderly patients with bone loss, ${ }^{70}$ supporting the hypothesis of increased inflammation with aging. ${ }^{71}$ In fact, TNF-a promotes bone resorption by both directly inducing osteoclast differentiation ${ }^{72}$ and inhibiting osteoblast differentiation and function. ${ }^{73,74} \mathrm{LL}-1$ drives osteoclast differentiation via a RANKL/RANK-independent mechanism. ${ }^{75}$ IL- 6 indirectly plays a positive role in osteoclast differentiation by binding IL- 6 receptors expressed on osteoblastic cells to induce RANKL expression. ${ }^{76}$ Neutrophils stimulate osteoclastogenesis by upregulating cell surface RANKL expression under TLR stimulation ${ }^{77}$ or by inducing osteoblast retraction. $^{78}$ Interferon gamma (IFN- $\gamma$ ), secreted by anti-inflammatory macrophages (M2), inhibits osteoclast differentiation via rapid degradation of TRAF6. ${ }^{79}$ However, macrophage polarization shows a shift toward macrophages (M1) that promote inflammatory cytokines as a consequence of aging. ${ }^{80}$ In contrast, mature $B$ cells are important regulators of a decoy receptor for RANKL, osteoprotegerin (OPG). In total, $40 \%$ of the OPG in bone marrow is produced by mature $B$ cells alone. ${ }^{81}$ The increased bone resorption and low levels of bone marrow OPG were demonstrated in B cell-deficient mice; this defect can be normalized by the transplantation of $B$ cells. As a result of the decreased number of mature human B cells, the supply of OPG is low in patients with osteoporosis. Thus, current evidence supports that the high RANKL/OPG ratio caused by agingrelated inflammation and the lack of mature $B$ cells is associated with the hyperactivation of osteoclastogenesis and aggravation of bone resorption in elderly patients with bone loss, which increases the incidence of further intraoperative or postoperative fractures (Fig. 2). Moreover, Nagae et al. concluded that overactivation of osteoclasts plays an important role in chronic pain after osteoporotic fracture by creating acidosis. ${ }^{82}$ Hyper osteoclast activity may lead to pathological modifications of bone sensory nerve fibers, with an overexpression of acidsensitive pain receptors, which contributes to generating and maintaining pain in osteoporosis. ${ }^{83}$

\section{MOLECULAR BASIS OF BONE MECHANOSENSATION}

Primary fracture healing occurs when the fracture site achieves rigid anatomical and mechanical fixation. Under these conditions, a soft callus enveloping the bone extremities subsequently calcifies to a peripheral solid callus by intramembranous ossification. ${ }^{35}$ However, in elderly osteoporotic bones, the healing process will be more like indirect bony union by forming a periosteal callus bridging the fracture gap, since it is usually difficult for the compromised bones to maintain enough stress stimulation. ${ }^{84}$ Among the bone multicellular units (BMUs), which consist of various cells involved in bone remodeling, the osteocytes embedded in the matrix function as major mechanosensitive cells. ${ }^{85}$ Substantial evidence indicates that the mechanosensation of osteocytes is mediated by signaling molecules, such as Wnts, bone morphogenetic proteins (BMPs), nitric oxide (NO), and prostaglandin E2 (PGE2) in response to mechanical stimulation. ${ }^{86}$ Furthermore, altered enzyme activity and RNA synthesis have been reported in osteoclasts after mechanical loading of intact bone, which further supports the mechanosensory role of osteocytes in bone. ${ }^{87}$ Thus, adequate mechanical loading and mechanotransduction are pivotal factors in the repair and remodeling phase of fracture healing.

Mechanical forces, including fluid flow as well as compressive/ tensile forces in the $\mathrm{LCN}^{13}$ induce cell-level physical signals of shear stress, electric/streaming potentials, and substrate strain by acting on cell surface sensors and within the signaling pathways. ${ }^{88}$ To date, evidence strongly suggests that integrins on the surface 
Hematoma and inflammatory phases

Elderly osteoporotic bones

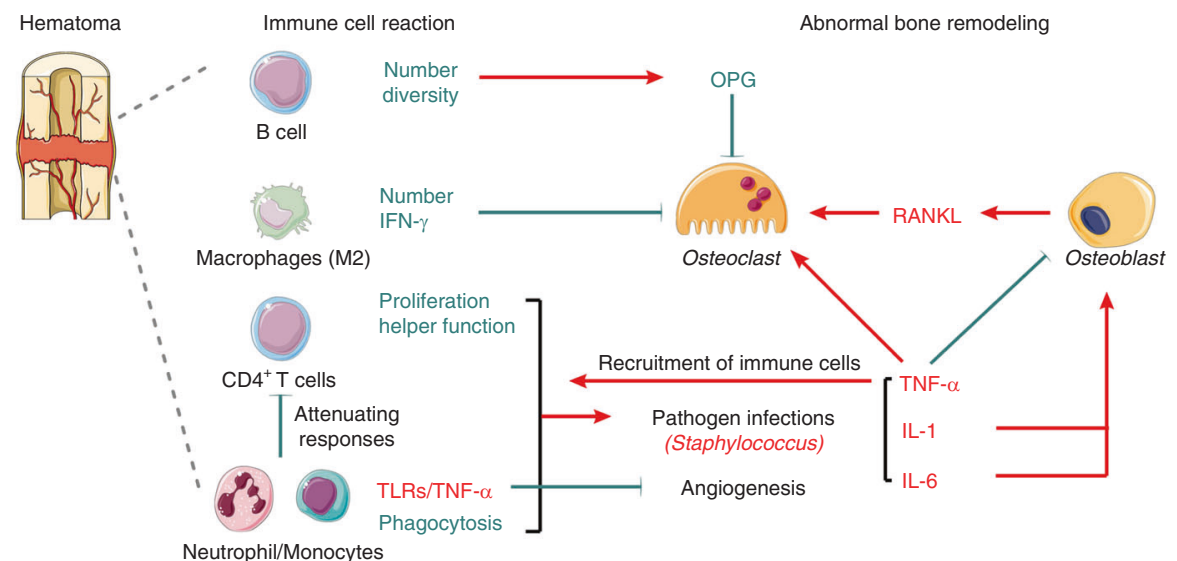

Fig. 2 Osteoimmunology in elderly osteoporotic bones. Hematoma and inflammatory phases are the immediate reactions to a fracture. The limited inflammatory response at the fracture site is essential to initiate repair processes and mobilize all the required factors involved in the early bridging of the fracture gap, especially in indirect bony unions without rigid fixation. The high RANKL/OPG ratio caused by aging-related inflammation and the lack of mature B cells is associated with the hyperactivation of osteoclastogenesis and aggravation of bone resorption in elderly patients with bone loss, which increases the incidence of intra- or postoperative further fractures. OPG osteoprotegerin, IFN- $\gamma$ interferon gamma, RANKL receptor activator of nuclear factor kappa-B ligand, TLRs toll-like receptors, TNF- $\alpha$ tumor necrosis factor alpha, IL- 1 interleukin-1, IL-6 interleukin-6. "Red" refers to upregulation; "Green" refers to downregulation

of bone cells are ubiquitous sensors of mechanical forces capable of detecting alterations in the mechanical environment in the extracellular milieu. ${ }^{89}$ Shear strain is detected by primary cilia via polycystin 1 (PC1) and transient receptor potential cation channel subfamily $\mathrm{V}$ member 4 (TRPV4), which activate signal transducer and activator of transcription (STAT) signals to induce ion flux. ${ }^{90}$ Wnt signaling is also activated by cilia via the noncanonical pathway, resulting in $\beta$-catenin degradation. ${ }^{91,92}$ The role of canonical Wnt in the suppression of the SOST gene (sclerostin) has also been demonstrated. ${ }^{93}$ Furthermore, fluid shear stress can activate voltage-sensitive calcium channels on the plasma membrane, leading to influx of $\mathrm{Ca}^{2+}$, which induces PGE2 synthesis via ATP and inhibits NO generation as a second messenger. ${ }^{94,95}$ PGE2 and ATP are released via connexin hemichanels formed following extracellular signal-regulated kinase $1 / 2$ (ERK1/2)-induced transcription of connexin-43 (Cx43). ${ }^{96,97}$ Compressive/tensile forces impose hydraulic pressure in the lacunarcanalicular system, ${ }^{89}$ which increases cellular deformation of osteocytes ${ }^{98}$. The substrate strain at the membrane can be sensed by integrins that transmit force to the cell cytoskeleton via ERK, proto-oncogene tyrosine-protein kinase Src (SRC) and replication origin activator (ROA) to induce stress fiber polymerization. ${ }^{98}$ The cell nucleus plays crucial roles in response to cellular mechanotransduction. Transcriptional regulation in the cell nucleus converts incoming mechanoresponsive signals into biological signaling and even directly responds to cellular deformation. ${ }^{99}$ These intracellular signaling pathways converge to modulate osteogenic transcription factors in addition to regulators of growth factors and matrix proteins required for osteogenesis. Evidence suggests that mechanical signals induce OPG and suppress RANKL to inhibit osteoclast differentiation. ${ }^{100}$

The morphological changes of osteocytes with aging have been reported to influence their mechanosensitivity and the response to loads. ${ }^{101}$ Changes in LCN volume due to the increased rate of osteocytic osteolysis with aging or trauma have been shown to affect local bone mechanosensation. ${ }^{102}$ Additionally, age-related changes in periosteal modeling arise from cell function/signaling deficits combined with increased marrow adiposity leading to a reduced pool of osteoblast progenitors. ${ }^{103,104}$ Furthermore, periosteal lining cell numbers and osteoblast life-span are reduced by an increased rate of apoptosis. ${ }^{105}$ There is an age-related switch in macrophage differentiation from the anti-inflammatory (M2) phenotype that mediates tissue repair to the inflammatory (M1) phenotype. ${ }^{53}$ As a consequence of the decline in the secretion of anti-inflammatory and osteogenic cytokines, the bone regeneration capability could be impaired in the process of remodeling osteoporotic fractures. ${ }^{7}$ In osteoporotic fractures, the inevitable immobilization and stress shielding achieved by orthopedic surgery reduce the mechanical loading compared with that at normal sites. ${ }^{106}$ The deficiency of stress loading on surface sensors of bone cells is accompanied by NF-KB activation of osteoblasts and neighboring immune cells that promotes RANKL production to trigger osteoclastogenesis and bone resorption. ${ }^{107,108}$ This process results in the excess removal of bone mass, ${ }^{93}$ which therefore leads to a coarse trabecular pattern and thinning of cortical bone. Estrogen controls the adaptation of osteoblasts and osteocytes to mechanical loads via binding to the estrogen receptor (ER) or activation of TGF1 receptors. ${ }^{109}$ Delayed ER expression was shown to be correlated with impaired callus formation capacity in the healing process. ${ }^{110} \mathrm{~A}$ study in humans suggested that mechanical interventions enhance periosteal modeling and bone strength in the young skeleton, ${ }^{111}$ while the effects are markedly diminished in the elderly skeleton. ${ }^{11,112}$ In vitro studies indicate that the age-related increase in osteocyte degradation and reduction in the basal level of mechanosensation significantly affect second messenger signaling to modulate bone regeneration ${ }^{111}$ (Fig. 3). An optimal strategy for improving the treatment of osteoporotic fractures must address both biological and mechanical issues based on the molecular mechanisms of mechanical loading in fracture healing. ${ }^{93}$

\section{ANTI-INFLAMMATORY EFFECTS OF MECHANICAL LOADING}

After the fracture gap has been bridged by a callus, the woven bone is slowly replaced with lamellar bone structures. Balanced resorption and formation of new bone require a normal 


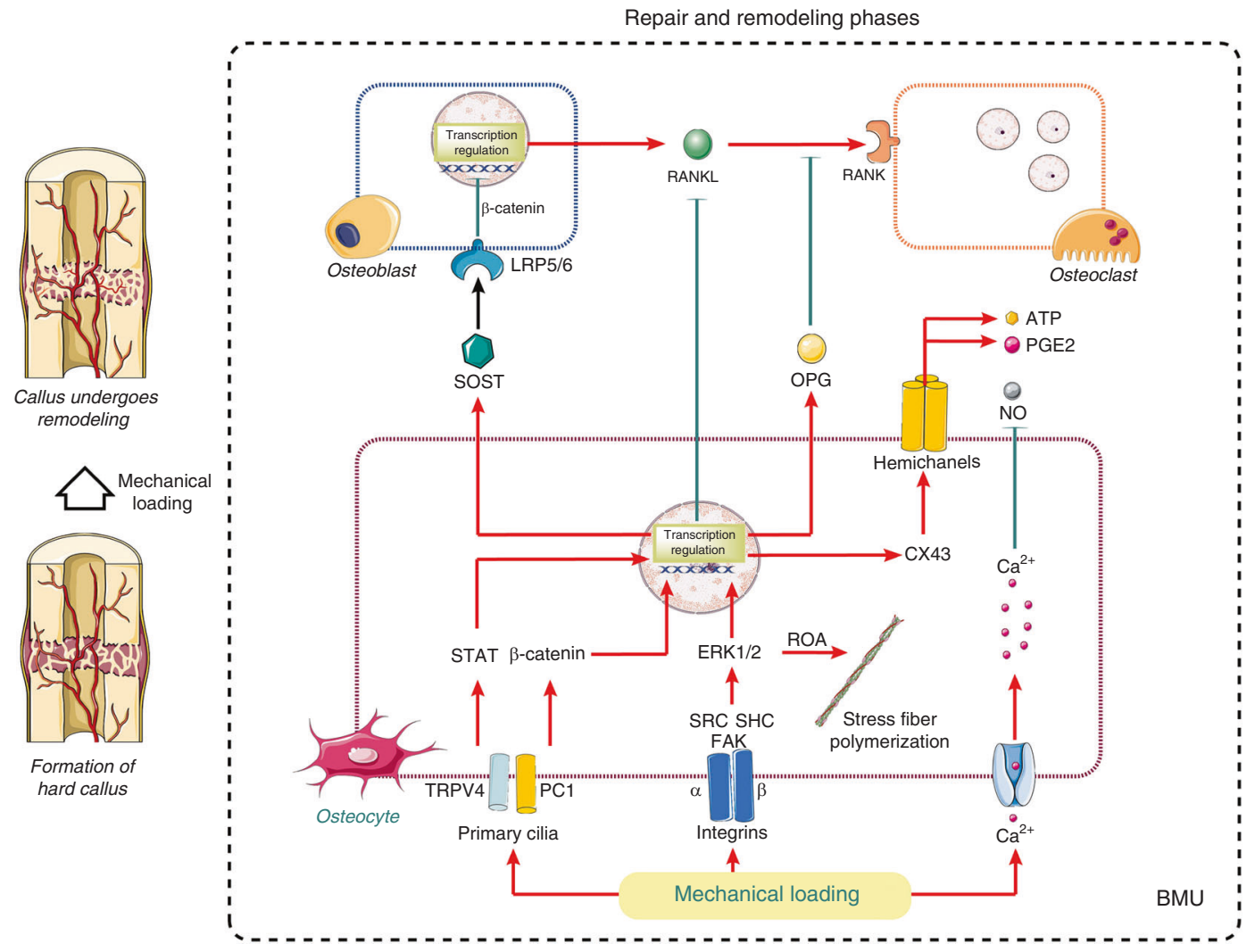

Fig. 3 Molecular basis of bone mechanosensation. The bone multicellular unit (BMU), which consists of osteocytes, osteoblasts, and osteoclasts, functions as a large mechanosensitive organ. Mechanical loading can be sensed by primary cilia, integrins, and $\mathrm{Ca}^{2+}$ channels on the surface of bone cells, then transcribed in the nucleus with inhibition of RANKL production and promotion of sclerostin and OPG. LRP5/6, low-density lipoprotein receptor-related protein 5/6; SOST sclerostin, RANKL receptor activator of nuclear factor kappa-B ligand, RANK receptor activator of nuclear factor kappa-B, OPG osteoprotegerin, ATP adenosine triphosphate, PGE2 prostaglandin E2, NO nitric oxide, CX43 connexin-43, STAT signal transducer and activator of transcription, ERK1/2 extracellular signal-regulated kinase1/2, ROA replication origin activator, TRPV4 transient receptor potential cation channel subfamily $V$ member 4, PC1 polycystin 1, SRC proto-oncogene tyrosine-protein kinase Src, SHC Shc-transforming protein, FAK focal adhesion kinase, BMU bone multicellular unit. "Red" refers to upregulation; "Green" refers to downregulation

environment without excessive inflammation. ${ }^{37}$ In these longterm phases, mechanics play a pivotal role, not only as the forces driving remodeling but also as the regulators that function to inhibit inflammation and abrogate the associated repression of growth factors and matrix synthesis. ${ }^{113}$ The traumatic signals caused by fracture and surgery initiate pro-inflammatory signaling cascades via activation of NF-KB transcription factors. ${ }^{114,115} \mathrm{NF}-\mathrm{KB}$ activation leads to the production of high levels of $\mathrm{NO}$ and superoxide that mediate both bone damage and matrix degradation. ${ }^{116}$ Mediators such as TNF- $\alpha$, IL-1 $\beta$, and matrix metalloproteinases (MMPs) play key roles in the pathogenesis of inflammatory bone diseases and injuries. ${ }^{117}$ In IL-1 $\beta$-treated osteoblast-like cells, mechanical signals have been shown to rapidly (within $10 \mathrm{~min}$ ) and dramatically inhibit NF-KB nuclear translocation. ${ }^{118}$ The mechanism involves the inhibition of TNF receptor-associated factor 6 (TRAF6) phosphorylation and subsequent activation of the inhibitor of NF-KB kinase (IKK) complex. ${ }^{119}$ This process prevents the proteosomal degradation of NF-KB inhibitor alpha (IKBa) and NF-KB inhibitor beta ( $\mathrm{KB} \beta$ ) phosphorylation, which in turn inhibits nuclear translocation of NF-KB and subsequent pro-inflammatory gene transcription. ${ }^{120}$ In fact, mechanotransduction at low magnitudes is a potent anti-inflammatory signal ${ }^{121}$ that counters the NF-KB signaling cascade. ${ }^{122}$ In vitro studies in osteoblasts have shown that the pro-inflammatory mediators suppressed by mechanical signals (tensile, compressive, and shear) include IL$1 \beta$-induced NO, COX-2, PGE2, cytokines (IL-1 $\beta$ and TNF- $\alpha$ ), and
MMPs. $^{123}$ Simultaneously, mechanical signals upregulate the expression of growth factors, such as BMPs, OCN, and alkaline phosphatase (ALKP), which are inhibited during inflammation. ${ }^{124}$ Several anti-inflammatory cytokines (IL-10) and tissue inhibitors of metalloproteinases (TIMPs) that are inhibited during inflammation are upregulated by mechanical signals. For instance, IL-10 and TIMP-II synthesized by low magnitudes of mechanical signals can suppress inflammation and matrix breakdown in osteoblast and osteoblast-like cells. ${ }^{125}$ In contrast, exogenous PGE2 was demonstrated to function as an intercellular messenger for enhancement of the mechanosensitivity of bone to loading forces both in vitro and in vivo. ${ }^{126}$ Furthermore, in the presence of PGE2 signaling, osteocytes release NO in response to mechanical stimulation via cytoskeletal adaptation and mitogen-activated protein kinase (MAPK) pathways. ${ }^{127}$ Additionally, mechanical loading increases ER-a expression at the fracture callus, which is beneficial for mechanical signal transduction and fracture repair. ${ }^{128,129}$ These data indicate that rigid fixation and adequate mechanical loading are a means of improving the immune environment that benefits bone healing ${ }^{130}$ (Fig. 4).

\section{MANAGEMENT OF HEMATOMA AND PERIOPERATIVE INFECTION}

The most satisfactory bone healing depends on a good biological environment and appropriate mechanical loading for bone repair 


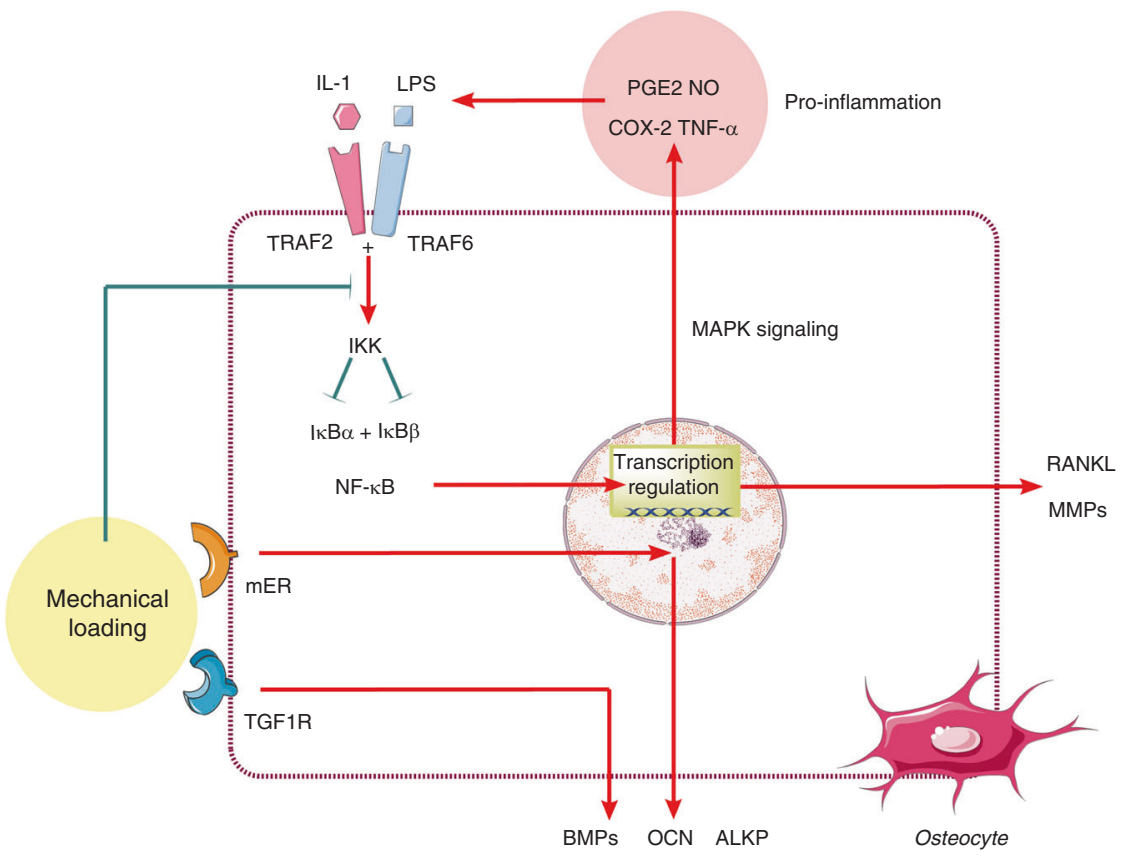

Fig. 4 Anti-inflammatory effects of mechanical loading. The mechanotransduction at low magnitudes is a potent signal to counter inflammation activated by the NF-кB signaling cascade. IL-1 interleukin-1, LPS lipopolysaccharide, TRAF2 TNF receptor-associated factor 2, TRAF6 TNF receptor-associated factor 6, PGE2 prostaglandin E2, NO nitric oxide, COX-2 cyclooxygenase-2, TNF- $\alpha$ tumor necrosis factor alpha,

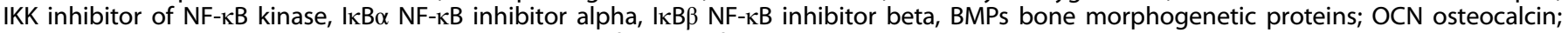
ALKP alkaline phosphatase; RANKL receptor activator of nuclear factor kappa-B ligand, MAPK mitogen-activated protein kinase, MMPs matrix metalloproteinases. "Red" refers to upregulation; "Green" refers to downregulation

and remodeling. Orthopedic surgeons are encouraged to familiarize themselves with the molecular basis of skeletal senescence, mechanical loading and osteoimmunology in osteoporotic fractures, which is critical for determining an appropriate surgical technique or nonsurgical intervention ${ }^{3}$. In terms of the decrease in early immune responses and pathogen clearance in aged patients with osteoporotic fractures, special preoperative management is required to achieve a better local healing environment. Previous studies have revealed the osteoimmunological role of hematoma in fracture healing, especially in the inflammatory phase. ${ }^{42,131}$ However, there is still no consensus on hematoma management among surgeons. Grundnes and Reikeras reported that early removal of the hematoma (2-7 days) after fracture greatly prohibited bone healing in an animal fracture model. ${ }^{132}$ Other researchers, however, found that hematoma without normal fibrinolysis was an obstacle to cellular trafficking, which subsequently inhibited fracture healing by impeding macrophage accumulation. ${ }^{133}$ Thus, in clinical practice, early hematoma in the fracture site should be preserved and induced to "mature". Indeed, the use of fibrin biomaterials, including platelet-rich plasma (PRPs), platelet-rich fibrin (PRFs) and other treatments, ${ }^{134}$ mimicking the structure of the natural hematoma, has demonstrated promising effects on the improvement of fracture healing. In addition, earlystage treatment with recombinant human platelet-derived growth factor-BB (rhPDGF-BB) could be beneficial for vascularization and angiogenesis in local sites, ${ }^{135}$ which would promote the recruitment of progenitors and accelerate bone remodeling in fracture healing of the elderly. ${ }^{136}$ In short, hematoma is a natural factor that enhances fracture healing and should be preserved in fracture sites, although thorough mechanisms are needed to be well investigated. Due to the decline of immune responses and pathogen clearance dysfunction in elderly patients with osteoporotic fractures, the prevention of perioperative infection through the use of adequate doses of antibiotics is important for maintaining a normal environment for initiating fracture healing (Fig. 5). Consequently, in orthopedic surgery, antibiotics, such as antibiotic-augmented acrylic cements/beads are increasingly used in topical form. ${ }^{137}$ However, the enhanced antibiotic treatment doses are thousands of times higher than those required to inhibit bacterial growth. ${ }^{137}$ Current evidence suggests that this concentration is detrimental to abnormal bone remodeling as a result of negative effects on mitochondrial physiology. ${ }^{137}$ Thus, local antibiotic vehicles must be designed to deliver sufficiently high concentrations to inhibit bacterial growth without affecting bone cell metabolism. ${ }^{138}$

\section{ANTI-INFLAMMATION AND REGULATION OF BONE REMODELING}

Increased RANKL/OPG ratios caused by aging-related inflammation are associated with hyperactivation of osteoclastogenesis and exacerbation of bone resorption in elderly patients, leading to subsequent impairment of bone healing and inflammatory pain. Anti-inflammation therapy is a potential strategy that may benefit aging-related osteoporotic fracture by reducing inflammation and providing protection against bone loss. Studies have shown that healthy transgenic mice injected with anti-TNF-a repeatedly promote $T$ cell responses to cognate peptide antigen. ${ }^{139}$ In the clinical setting, anti-TNF-a (infliximab, Remicade) rapidly and remarkably restores the responses of $T$ cells from rheumatoid arthritis (RA) patients. ${ }^{56}$ Treatment with infliximab protects against bone loss and improves the formation/resorption marker ratio in this population, suggesting beneficial systemic and local bone effects. ${ }^{40,141}$ Although anti-inflammatory therapies have not been used clinically to treat osteoporosis, they have shown good promise in mouse models. Indeed, pharmacological or genetic ablation of TNF ${ }^{142}$ and IL-1 ${ }^{143}$ by somatic gene therapy ${ }^{144}$ has been used effectively to prevent ovariectomy-induced bone loss in mice. Thus, anti-inflammation therapy is a potential strategy that may benefit osteoporosis patients because of reduced 


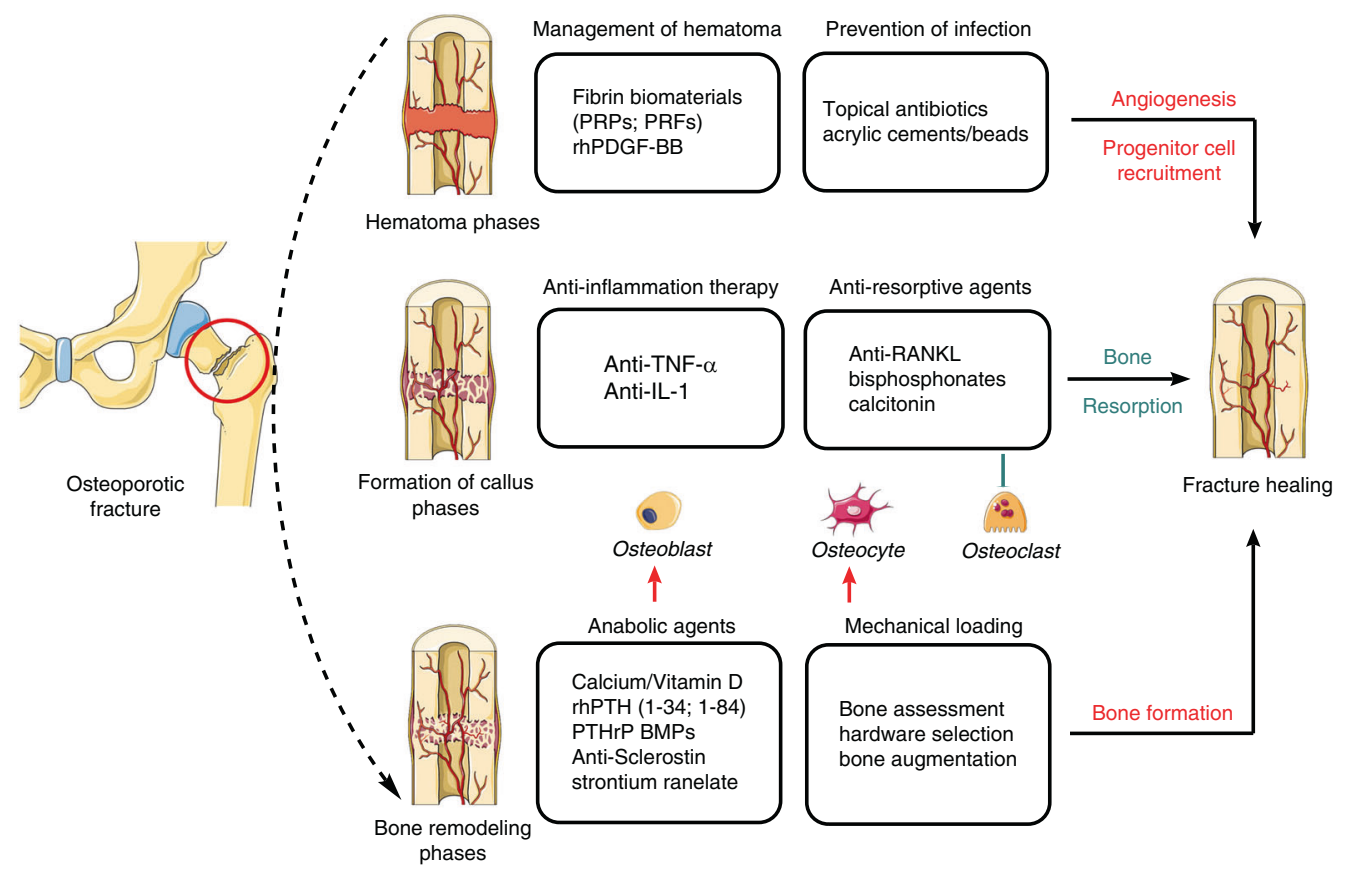

Fig. 5 Bench-to-bedside strategies for osteoporotic fracture. The most satisfactory bone healing depends on two pivotal factors: a good biological environment and appropriate mechanical loading for bone repair and homeostasis. Bench-to-bedside strategies, including management of hematomas and perioperative infections, anti-inflammation and regulation of bone resorption, and rigid fixation and mechanical loading enhancement would benefit the creation of the proper environment for fracture healing of osteoporotic bones. PRPs platelet-rich plasma, PRFs platelet-rich fibrin, rhPDGF-BB recombinant human platelet-derived growth factor-BB, TNF- $\alpha$ tumor necrosis factor alpha, IL-1 interleukin-1, RANKL receptor activator of nuclear factor kappa-B ligand, rhPTH recombinant human parathyroid hormone, PTHrP parathyroid hormone-related protein, BMPs bone morphogenetic proteins. "Red" refers to upregulation; "Green" refers to downregulation

inflammation in addition to protection against bone loss. However, the risk of infection is increased in patients undergoing anti-inflammation treatment, suggesting that anti-inflammatory drugs should be discontinued for a period of time before surgery. ${ }^{145}$ Because chronic inflammation affects bone healing, the anti-inflammatory drug should be reused in osteoporotic fracture after an acute immune response to alleviate inflammation-induced bone loss.

The recent development of antiresorptive agents (e.g., bisphosphonates, RANKL inhibitor) represents a significant advance in therapeutic options for improving bone quality and metabolism. ${ }^{146}$ Bisphosphonates are commonly used in osteoporosis to prevent and reduce pain by modifying osteoclast activity. ${ }^{147}$ Following an osteoporotic fracture, early intervention with antiresorptive drugs after surgery would not affect fracture union. ${ }^{148}$ However, bisphosphonate-dependent repair processes become progressively dominant in the late phases, suggesting that continuous administration of alendronate causes delayed healing in mechanically compromised situations. ${ }^{149}$ Denosumab, a RANKL inhibitor, can significantly reduce the high RANKL/OPG ratio in the inflammatory and repair phases of fracture healing with agingrelated osteoporosis ${ }^{150}$ and has been identified as an efficacious osteoporosis treatment option with low rates of adverse events. ${ }^{151}$ Calcitonin effectively relieves bone pain and can reduce bone loss in osteoporotic fractures, although short-term ( 3 months) use is recommended. ${ }^{152,153}$ In summary, reducing the frequency of postoperative syndromes in patients with osteoporosis requires not only regulation of the immune response but also balanced bone resorption and osteogenesis (Fig. 5). Studies have demonstrated that anti-inflammation therapy combined with a bone resorption blocking drug ${ }^{154}$ reverses systemic bone loss, ${ }^{155}$ while the timing and extent of immune intervention require further clinical exploration.

\section{STRATEGIES FOR MECHANICAL LOADING ENHANCEMENT AND RIGID FIXATION}

The biochemical responses of osteocytes to mechanical loads are mediated by signals induced via a variety of mechanosensitive proteins, such as primary cilia, integrins, and activated ion channels. ${ }^{156}$ However, it is as yet unclear how osteocytes perceive and differentiate responses to two drastically opposite magnitudes of mechanical signals, that is, those of physiological magnitudes that initiate regenerative responses and of traumatic signals that initiate bone damage and resorption. ${ }^{87}$ Appropriate use of bone formation promoters (e.g., calcium/vitamin D), mainly for osteoblasts and osteocytes, helps to further enhance the mechanical induction and repair of bone structure. Patients over 65 years old with BMD less than $-2.5 \mathrm{SD}$ or postmenopausal women with multiple osteoporotic vertebral fractures or hip fractures who have not responded to bisphosphonate therapy should be switched to the available anabolic agents, ${ }^{7,131}$ including recombinant human parathyroid hormone (rhPTH,[1-34] [1-84]) and parathyroid hormone-related protein (PTHrP). ${ }^{30}$ Strontium ranelate is now considered effective in enhancing the biomechanical properties of bone for resistance fragility fractures. Strontium ranelate increases bone formation and decreases bone resorption, thereby rebalancing bone remodeling, which is conducive to new bone formation. ${ }^{157}$ Numerous studies have shown that strontium ranelates functions in improvement in all parameters related to bone quality and strength. ${ }^{158}$ The sclerostin monoclonal antibody, such as romosozumab, has been shown to lead to gains in hip BMD. ${ }^{159}$ In addition, BMPs, which belong to transforming growth factor-beta (TGF- $\beta$ ) family members, ${ }^{160}$ lead to synergistic induction of downstream TGF $\beta$ signaling for osteogenesis combined with physical microenvironment. ${ }^{161}$ Tricalcium phosphate and polymethylmethacrylate (PMMA) are usually employed to augment bone cement and increase the stability of implant fixation in 
osteoporotic bone. ${ }^{162,163}$ These cements undergo interdigitation in porous bone ${ }^{38}$ to increase the surface area of contact and provide additional resistance against the screw threads. PMMA has also been used for the delivery of drugs, such as antibiotics, via bone cements. ${ }^{164}$ However, PMMA undergoes an exothermic reaction during the drying process, with the potential to initiate thermal bone necrosis. ${ }^{165}$ In addition, PMMA is difficult to remove in cases of revision or infection without integrating into the bony architecture. ${ }^{166}$ In contrast, the integration of tricalcium phosphate into the bone provides a potential scaffold for biological activity and cell growth in a demineralized bone matrix. ${ }^{167}$ Allograft fibulas are used in bone with low BMD as tools for reduction as well as the provision of medial calcar support. ${ }^{168}$ As mechanical stimulation is a potent anti-inflammatory signal, sufficient postsurgery mechanical loading interventions, including physical therapy and rehabilitation, are helpful for building a supportive mechanical and biological environment around the local fracture sites for bone healing. Low intensity vibration (LIV) improves bone quality by activating cells responsible for bone remodeling and biasing the differentiation of mesenchymal and HSC progenitors toward osteoblastogenesis. ${ }^{169,170}$ However, current evidence is insufficient to support the benefit of ultrasound and extracorporeal shockwave therapies (ECSW) for fracture healing in clinical practice ${ }^{171}$ (Fig. 5).

Mechanical bone strength is vital for the stable anchorage of hardware required for fracture repair. Due to the impaired bone strength and complicated immunology environment in elderly individuals with osteoporosis, more suitable implants with better mechanical characteristics are required to improve aging-related osteoporotic fracture healing. Measurement of the thickness and porosity of cortical bone prior to surgery is important in guiding hardware selection for the repair of osteoporotic fractures. Thus, it is of great importance to identify parameters for evaluating bone quality (Fig. 5). Only $60 \%$ of the variation in bone densitometry was measured by dual-energy X-ray absorptiometry (DXA) because it is hard to recognize differences in both trabecular and cortical bone geometrical macrostructure. ${ }^{172}$ Both trabecular connectivity and cortical porosity significantly influence bone strength parameters, including stiffness to resist deformation and elasticity to absorb energy. ${ }^{173}$ To determine a better intervention, state-of-the-art clinical imaging techniques will help in measuring bone structural parameters, instead of focusing on BMD alone. ${ }^{174}$ Evaluation of the grayscale intensity map of DXA imaging can provide more precise information for bone structural parameters

\begin{tabular}{|c|c|c|c|c|c|c|}
\hline Bicortical lag screw & $\begin{array}{l}\text { Potential improvement of thread } \\
\text { purchase }\end{array}$ & $\begin{array}{l}\text { BMD, TBS } \\
\text { SMI } \\
\text { BV/TV }\end{array}$ & $\begin{array}{l}\text { DXA } \\
\text { HR-pQCT }\end{array}$ & $\begin{array}{l}\text { Medial malleolus } \\
\text { fractures }\end{array}$ & & $185,198,199$ \\
\hline Traditional plates & $\begin{array}{l}\text { Compress the fracture fragments } \\
\text { between bone implant interface } \\
\text { to create fixation strength }\end{array}$ & $\begin{array}{l}\text { BMD } \\
\text { Bone } \\
\text { stiffness and } \\
\text { strength }\end{array}$ & DXA & Regular fractures & $\begin{array}{l}\text { Decrease of the axial and } \\
\text { torsional stiffness }\end{array}$ & $190,200,201$ \\
\hline Intramedullary nail & $\begin{array}{l}\text { Preserving the soft tissues around } \\
\text { fracture site }\end{array}$ & $\begin{array}{l}\text { BMD } \\
\text { Cortical } \\
\text { thickness }\end{array}$ & $\begin{array}{l}\text { DXA } \\
\text { QCT }\end{array}$ & $\begin{array}{l}\text { Proximal humerus } \\
\text { fractures }\end{array}$ & $\begin{array}{l}\text { A larger-diameter nail is } \\
\text { required to achieve a } \\
\text { diaphyseal fit and stability }\end{array}$ & 191,203 \\
\hline $\begin{array}{l}\text { Bone } \\
\text { augmentation }\end{array}$ & $\begin{array}{l}\text { Increase surface area; PMMA } \\
\text { carries osteogenic and antibiotic } \\
\text { drugs; Tricalcium phosphate and } \\
\text { Allograft fibulas act more as a } \\
\text { scaffold }\end{array}$ & $\begin{array}{l}\text { BMD } \\
\text { SMI } \\
\text { BV/TV } \\
\text { BMSi }\end{array}$ & $\begin{array}{l}\text { DXA } \\
\text { QCT }\end{array}$ & $\begin{array}{l}\text { Femoral neck } \\
\text { fractures } \\
\text { Spine fractures } \\
\text { Comminuted } \\
\text { proximal humerus } \\
\text { fractures }\end{array}$ & $\begin{array}{l}\text { Damage surrounding soft } \\
\text { tissues or initiate thermal } \\
\text { bone necrosis; Difficult } \\
\text { to remove }\end{array}$ & $\begin{array}{l}38,162- \\
164,196,204,205\end{array}$ \\
\hline
\end{tabular}

$B M D$ bone mineral density, DXA dual-energy X-ray absorptiometry, QCT quantitative computed tomography, HR-pQCT high-resolution peripheral QCT, $\mu M R I$ micromagnetic resonance imaging, TBS trabecular bone score, $B M S i$ bone material strength index, $P M M A$ polymethylmethacrylate, $S M I$ structure model index, $B V / T V$ bone volume fraction 
compared with BMD measurement. ${ }^{175}$ The trabecular bone score (TBS) correlates positively with trabecular connectivity based on evaluation of the DXA image. ${ }^{176}$ Combining TBS and BMD measurements provides an improved prediction of bone strength compared with BMD alone. ${ }^{177,178}$ Evaluations of structural, material, and mechanical properties based on bone biopsy specimens provide a reliable assessment of local bone characteristics, which are vital independent determinants of bone strength. ${ }^{179}$ The DensiProbe can be a helpful tool for intraoperative assessment of mechanical peak torque in mechanical testing setups, ${ }^{180}$ providing information that can be valuable in choosing implants. Furthermore, this approach does not increase the risk to the patient or increase the surgeon's workload since the central peg hole can be used for the next procedure. ${ }^{180}$ Cortical and cancellous screws are traditional designs, with the former having relatively narrower outer diameters and decreased thread pitch. ${ }^{181}$ In both cases, the fixation strength depends on the torque generated between the bone and thread that resists shear. ${ }^{182}$ During insertion of a cancellous bone screw into the osteoporotic bone, the torque reaches the plateau prior to the contact of all the screw threads. ${ }^{183}$ The changes in screw geometry that confer an advantage on cancellous screws are lost below a threshold BMD of $0.4 \mathrm{~g} \cdot \mathrm{cm}^{-1} .{ }^{184}$ The plateau torque (T Plateau), which is an efficient predictor of insertion failure at the femoral head, is significantly dependent on aspects of the bone microarchitecture, such as the structure model index (SMI) and bone volume fraction (BV/TV). ${ }^{185}$ Previous studies suggest that a more plate-like bone structure, a higher BV/TV, and a higher surface-to-volume ratio provide a structural environment that favors cutting of the screw threads into the bone, resulting in an increased T Plateau. ${ }^{186}$ Unstable and comminuted fracture patterns as well as early implant-bone fatigue in osteoporotic bones lead to implant loosening and fixation failure. ${ }^{3}$ Locking-plate technology provides a more advantageous biomechanical environment that facilitates the formation of a fixed angle between the plate and screw. ${ }^{187}$ Despite the greater overall stability, locking plates may create an excessively rigid construct, which is predisposed to peri-implant fracture. ${ }^{188}$ In proximal humeral fractures with low BMD, ${ }^{189}$ computed tomography (CT) assessments suggest that locking plates do not reduce the rate of mechanical failure. In elderly patients with low BMD, tibial plateau fracture is associated with increased comminution and compromised fixation, suggesting that external fixation might be a more effective option than dual plating. ${ }^{190}$ An intramedullary nail (IMN) is a load-sharing device with the advantage of promoting secondary bone healing while preserving the surrounding soft tissues and minimizing fractureinduced hematomas. ${ }^{191}$ The loss of interlocking screw fixation can be mitigated through a number of strategies, including the application of washers and interlocking screws in multiple planes. However, cortical thinning of osteoporotic bone increases the intramedullary canal diameter, and a larger-diameter nail is required to achieve a diaphyseal fit and stability. Therefore, an early quantitative computed tomography (QCT) assessment of the cortical thickness is critical in using IMN in osteoporotic fractures. Intra-articular and complex fractures in patients with osteoporosis pose unique challenges for surgeons. These patients have inadequate subchondral bone quality to allow for anatomic reductions, and the stability of the implant is difficult to maintain after the reintroduction of weight-bearing and increased range of motion. ${ }^{192}$ Primary arthroplasty (total hip/knee/elbow arthroplasty) has been adopted to obtain adequate weight-bearing and early mobilization, which has a superior prognosis compared to internal fixation in acute acetabular fractures, displaced intraarticular tibial plateau fractures and complex distal humeral fractures. ${ }^{193}$ Despite the advent of locked anatomic plates, a majority of experts recommend arthroplasty in the context of poor bone quality and small fracture fragments (Table 1 ).

\section{CONCLUSION AND PERSPECTIVE}

Low bone mass and compromised bone structure in osteoporotic fractures are undesirable for the reduction and rigid fixation, and the decreased regeneration and mechanosensation ability of osteoporotic bone also affect the healing. The initiation of supportive management, including anti-inflammatory drugs and sufficient application of antibiotics, is key for creating the proper environment for bone repair and homeostasis in patients with osteoporotic fractures. The adverse effects of insufficient mechanical loading in bone healing are critical factors that should be considered around the orthopedic procedure. Bench-to-bedside strategies for bone augmentation and hardware selection should be made according to further elucidation of the biomechanics and molecular mechanisms involved in bone repair. Multidisciplinary collaboration will facilitate the improvement of overall osteoporotic care and the reduction of secondary fracture incidence.

\section{ACKNOWLEDGEMENTS}

This study is supported by the National Natural Science Foundation of China (81772369, 81401809, 81373150), CAMS Innovation Fund for Medical Sciences (CIFMS, 2017-I2M-3-001). L.Z. is supported by the Beijing Nova program (Z171100001117110). Y.G. is supported by the Beijing Natural Science Foundation (7192127). The original elements used in the figures are from Servier Medical Art (http://smart.servier.com/).

\section{ADDITIONAL INFORMATION}

Competing interests: The authors declare no competing interests.

\section{REFERENCES}

1. Brown, C. Osteoporosis: staying strong. Nature 550, S15-s17 (2017).

2. Sozen, T., Ozisik, L. \& Basaran, N. C. An overview and management of osteoporosis. Eur. J. Rheumatol. 4, 46-56 (2017).

3. Yaacobi, E., Sanchez, D., Maniar, H. \& Horwitz, D. S. Surgical treatment of osteoporotic fractures: an update on the principles of management. Injury $\mathbf{4 8}$ (Suppl. 7), S34-s40 (2017).

4. Feron, J. M. \& Mauprivez, R. Fracture repair: general aspects and influence of osteoporosis and anti-osteoporosis treatment. Injury 47(Suppl. 1), S10-S14 (2016).

5. von Ruden, C. \& Augat, P. Failure of fracture fixation in osteoporotic bone. Injury 47(Suppl. 2), S3-S10 (2016).

6. Smith, D. M., Khairi, M. R. \& Johnston, C. C. Jr. The loss of bone mineral with aging and its relationship to risk of fracture. J. Clin. Investig. 56, 311-318 (1975).

7. Bernatz, J. T. et al. Osteoporosis is common and undertreated prior to total joint arthroplasty. J. Arthroplast. 34, 1347-1353 (2019).

8. Singer, A. et al. Burden of illness for osteoporotic fractures compared with other serious diseases among postmenopausal women in the United States. Mayo Clin. Proc. 90, 53-62 (2015).

9. Clark, D., Nakamura, M., Miclau, T. \& Marcucio, R. Effects of aging on fracture healing. Curr. Osteoporos. Rep. 15, 601-608 (2017).

10. Baxter, M. A. et al. Study of telomere length reveals rapid aging of human marrow stromal cells following in vitro expansion. Stem Cells 22, 675-682 (2004).

11. Foulke, B. A., Kendal, A. R., Murray, D. W. \& Pandit, H. Fracture healing in the elderly: a review. Maturitas 92, 49-55 (2016).

12. Turner, C. H. Biomechanics of bone: determinants of skeletal fragility and bone quality. Osteoporos. Int.: 13, 97-104 (2002).

13. Florencio-Silva, R., Sasso, G. R., Sasso-Cerri, E., Simoes, M. J. \& Cerri, P. S. Biology of bone tissue: structure, function, and factors that influence bone cells. BioMed. Res. Int. 2015, 421746 (2015).

14. Iwaniec, U. T. \& Turner, R. T. Influence of body weight on bone mass, architecture and turnover. J. Endocrinol. 230, R115-R130 (2016).

15. van der Linden, J. C. \& Weinans, H. Effects of microarchitecture on bone strength. Curr. Osteoporos. Rep. 5, 56-61 (2007).

16. Stock, S. R. The mineral-collagen interface in bone. Calcif. Tissue Int. 97, 262-280 (2015).

17. Tzaphlidou, M. Bone architecture: collagen structure and calcium/phosphorus maps. J. Biol. Phys. 34, 39-49 (2008).

18. Guerado, E. et al. Bone mineral density aspects in the femoral neck of hip fracture patients. Injury 47(Suppl. 1), S21-S24 (2016). 
19. Qi, Z., Liu, W. \& Lu, J. The mechanisms underlying the beneficial effects of exercise on bone remodeling: roles of bone-derived cytokines and microRNAs. Prog. Biophys. Mol. Biol. 122, 131-139 (2016).

20. Katsimbri, P. The biology of normal bone remodelling. Eur. J. Cancer Care $\mathbf{2 6}$, https://doi.org/10.1111/ecc.12740 (2017).

21. Boyce, B. F., Rosenberg, E., de Papp, A. E. \& Duong, L. T. The osteoclast, bone remodelling and treatment of metabolic bone disease. Eur. J. Clin. Investig. 42, 1332-1341 (2012).

22. Li, C., Williams, B. O., Cao, X. \& Wan, M. LRP6 in mesenchymal stem cells is required for bone formation during bone growth and bone remodeling. Bone Res. 2, 14006 (2014).

23. Delaisse, J. M. The reversal phase of the bone-remodeling cycle: cellular prerequisites for coupling resorption and formation. Bone. Rep. 3, 561 (2014).

24. Lai, X. et al. The dependences of osteocyte network on bone compartment, age, and disease. Bone Res. 3, 15009 (2015).

25. Hadjidakis, D. J. \& Androulakis, I. I. Bone remodeling. Ann. New Y. Acad. Sci. 1092, 385-396 (2006).

26. Watson, E. C. \& Adams, R. H. Biology of bone: the vasculature of the skeletal system. Cold Spring Harbor Perspect. Med. 8, a031559 (2018).

27. Diab, D. L. \& Watts, N. B. Postmenopausal osteoporosis. Curr. Opin. Endocrinol. Diab. Obes. 20, 501-509 (2013).

28. Duque, G. \& Troen, B. R. Understanding the mechanisms of senile osteoporosis: new facts for a major geriatric syndrome. J. Am. Geriatr. Soc. 56, 935-941 (2008).

29. Marie, P. J. Bone cell senescence: mechanisms and perspectives. J. Bone Miner. Res. 29, 1311-1321 (2014).

30. Black, D. M. \& Rosen, C. J. Clinical practice. Postmenopausal osteoporosis. New Engl. J. Med. 374, 254-262 (2016).

31. Yamagishi, S. Role of advanced glycation end products (AGEs) in osteoporosis in diabetes. Curr. Drug Targets 12, 2096-2102 (2011).

32. Chen, H., Zhou, X., Fujita, H., Onozuka, M. \& Kubo, K. Y. Age-related changes in trabecular and cortical bone microstructure. Int. J. Endocrinol. 2013, 213234 (2013).

33. Osterhoff, G. et al. Bone mechanical properties and changes with osteoporosis. Injury 47(Suppl. 2), S11-S20 (2016).

34. Silva, M. J. Biomechanics of osteoporotic fractures. Injury 38(Suppl. 3), S69-S76 (2007).

35. Marsell, R. \& Einhorn, T. A. The biology of fracture healing. Injury 42, 551-555 (2011).

36. Einhorn, T. A. \& Gerstenfeld, L. C. Fracture healing: mechanisms and interventions. Nat. Rev. Rheumatol. 11, 45-54 (2015).

37. Claes, L., Recknagel, S. \& Ignatius, A. Fracture healing under healthy and inflammatory conditions. Nat. Rev. Rheumatol. 8, 133-143 (2012).

38. Rothberg, D. L. \& Lee, M. A. Internal fixation of osteoporotic fractures. Curr. Osteoporos. Rep. 13, 16-21 (2015).

39. Lu, C. et al. Cellular basis for age-related changes in fracture repair. J. Orthop. Res. 23, 1300-1307 (2005).

40. Ozaki, A., Tsunoda, M., Kinoshita, S. \& Saura, R. Role of fracture hematoma and periosteum during fracture healing in rats: interaction of fracture hematoma and the periosteum in the initial step of the healing process. J. Orthop. Sci. 5, 64-70 (2000)

41. Chan, J. K. et al. Low-dose TNF augments fracture healing in normal and osteoporotic bone by up-regulating the innate immune response. EMBO Mol. Med. 7, 547-561 (2015).

42. Timlin, M. et al. Fracture hematoma is a potent proinflammatory mediator of neutrophil function. J. Trauma 58, 1223-1229 (2005).

43. Gibon, E., Lu, L. \& Goodman, S. B. Aging, inflammation, stem cells, and bone healing. Stem Cell Res. Ther. 7, 44 (2016).

44. Briot, K., Geusens, P., Em Bultink, I., Lems, W. F. \& Roux, C. Inflammatory diseases and bone fragility. Osteoporos. Int. 28, 3301-3314 (2017).

45. Weng, N.-p Aging of the immune system: how much can the adaptive immune system adapt? Immunity 24, 495-499 (2006).

46. McKenna, R. W., Washington, L. T., Aquino, D. B., Picker, L. J. \& Kroft, S. H. Immunophenotypic analysis of hematogones (B-lymphocyte precursors) in 662 consecutive bone marrow specimens by 4-color flow cytometry. Blood 98, 2498-2507 (2001).

47. Frasca, D. et al. Aging down-regulates the transcription factor E2A, activationinduced cytidine deaminase, and Ig class switch in human B cells. J. Immunol. 180, 5283-5290 (2008).

48. Chong, Y. et al. CD27+ (memory) B cell decrease and apoptosis-resistant CD27(naive) B cell increase in aged humans: implications for age-related peripheral B cell developmental disturbances. Int. Immunol. 17, 383-390 (2005).

49. Weksler, M. E., Goodhardt, M. \& Szabo, P. The effect of age on B cell development and humoral immunity. Springe. Semin. Immunopathol. 24, 35-52 (2002).

50. Swain, S., Clise-Dwyer, K. \& Haynes, L. Homeostasis and the age-associated defect of CD4 T cells. Semin. Immunol. 17, 370-377 (2005).
51. Kovtun, A. et al. The crucial role of neutrophil granulocytes in bone fracture healing. Eur. Cells Mater. 32, 152-162 (2016).

52. Hearps, A. C. et al. Aging is associated with chronic innate immune activation and dysregulation of monocyte phenotype and function. Aging Cell 11, 867-875 (2012).

53. Sinder, B. P., Pettit, A. R. \& McCauley, L. K. Macrophages: their emerging roles in bone. J. Bone Miner. Res. 30, 2140-2149 (2015).

54. Shaw, A. C., Goldstein, D. R. \& Montgomery, R. R. Age-dependent dysregulation of innate immunity. Nat. Rev. Immunol. 13, 875-887 (2013).

55. Qian, F. et al. Age-associated elevation in TLR5 leads to increased inflammatory responses in the elderly. Aging Cell 11, 104-110 (2012).

56. Cope, A. P. et al. Chronic exposure to tumor necrosis factor (TNF) in vitro impairs the activation of $\mathrm{T}$ cells through the $\mathrm{T}$ cell receptor/CD3 complex; reversal in vivo by anti-TNF antibodies in patients with rheumatoid arthritis. J. Clin. Investig. 94, 749-760 (1994)

57. Frasca, D. et al. A molecular mechanism for TNF-a-mediated down-regulation of B cell responses. J. Immunol. (Baltim., MD: 1950) 188, 279-286 (2012).

58. Davis, L. S., Cush, J. J., Schulze-Koops, H. \& Lipsky, P. E. Rheumatoid synovial CD4 $+T$ cells exhibit a reduced capacity to differentiate into IL-4-producing Thelper-2 effector cells. Arthritis Res. 3, 54-64 (2001).

59. Isomaki, P. et al. Prolonged exposure of T cells to TNF down-regulates TCR zeta and expression of the TCR/CD3 complex at the cell surface. J. Immunol. (Baltim., MD: 1950) 166, 5495-5507 (2001).

60. Lim, J. C. et al. TNFalpha contributes to diabetes impaired angiogenesis in fracture healing. Bone 99, 26-38 (2017).

61. Oishi, Y. \& Manabe, I. Macrophages in age-related chronic inflammatory diseases. Npj Aging Mech. Dis. 2, 16018 (2016).

62. Blanchette, K. A., Prabhakara, R., Shirtliff, M. E. \& Wenke, J. C. Inhibition of fracture healing in the presence of contamination by Staphylococcus aureus: effects of growth state and immune response. J. Orthop. Res. 35, 1845-1854 (2017).

63. Kumar, A., Tassopoulos, A. M., Li, Q. \& Yu, F. S. Staphylococcus aureus protein A induced inflammatory response in human corneal epithelial cells. Biochem. Biophys. Res. Commun. 354, 955-961 (2007).

64. Olaru, F. \& Jensen, L. E. Staphylococcus aureus stimulates neutrophil targeting chemokine expression in keratinocytes through an autocrine IL-1alpha signaling loop. J. Invest. Dermatol. 130, 1866-1876 (2010).

65. Stenzel, W. et al. An essential role for tumor necrosis factor in the formation of experimental murine Staphylococcus aureus-induced brain abscess and clearance. J. Neuropathol. Exp. Neurol. 64, 27-36 (2005).

66. Liu, H. et al. Staphylococcus aureus epicutaneous exposure drives skin inflammation via IL-36-mediated T cell responses. Cell Host microbe 22, 653-666.e655 (2017).

67. Hofbauer, L. C. et al. Interleukin-1 beta and tumor necrosis factor-alpha, but not interleukin-6, stimulate osteoprotegerin ligand gene expression in human osteoblastic cells. Bone 25, 255-259 (1999).

68. Cenci, $\mathrm{S}$. et al. Estrogen deficiency induces bone loss by enhancing T-cell production of TNF-alpha. J. Clin. Investig. 106, 1229-1237 (2000).

69. Fuller, K., Murphy, C., Kirstein, B., Fox, S. W. \& Chambers, T. J. TNFalpha potently activates osteoclasts, through a direct action independent of and strongly synergistic with RANKL. Endocrinology 143, 1108-1118 (2002).

70. Scheidt-Nave, C. et al. Serum interleukin 6 is a major predictor of bone loss in women specific to the first decade past menopause. J. Clin. Endocrinol. Metab. 86, 2032-2042 (2001).

71. Cuturi, M. C. et al. Independent regulation of tumor necrosis factor and lymphotoxin production by human peripheral blood lymphocytes. J. Exp. Med. 165, 1581-1594 (1987).

72. Azuma, Y., Kaji, K., Katogi, R., Takeshita, S. \& Kudo, A. Tumor necrosis factor-a induces differentiation of and bone resorption by osteoclasts. J. Biol. Chem. 275, 4858-4864 (2000).

73. Gilbert, L. et al. Inhibition of osteoblast differentiation by tumor necrosis factoralpha. Endocrinology 141, 3956-3964 (2000).

74. Kitaura, H. et al. Immunological reaction in TNF-a-mediated osteoclast formation and bone resorption in vitro and in vivo. Clin. Dev. Immunol. 2013, 8 (2013).

75. Kim, J. H. et al. The mechanism of osteoclast differentiation induced by IL-1. J. Immunol. (Baltim., MD: 1950) 183, 1862-1870 (2009).

76. Udagawa, N. et al. Interleukin (IL)-6 induction of osteoclast differentiation depends on IL-6 receptors expressed on osteoblastic cells but not on osteoclast progenitors. J. Exp. Med. 182, 1461-1468 (1995).

77. Chakravarti, A., Raquil, M. A., Tessier, P. \& Poubelle, P. E. Surface RANKL of Tolllike receptor 4-stimulated human neutrophils activates osteoclastic bone resorption. Blood 114, 1633-1644 (2009).

78. Allaeys, I. et al. Osteoblast retraction induced by adherent neutrophils promotes osteoclast bone resorption: implication for altered bone remodeling in chronic gout. Lab. Investig. 91, 905-920 (2011). 
79. Takayanagi, H. et al. T-cell-mediated regulation of osteoclastogenesis by signalling cross-talk between RANKL and IFN-gamma. Nature 408, 600-605 (2000).

80. Schlundt, $C$. et al. Macrophages in bone fracture healing: their essential role in endochondral ossification. Bone 106, 78-89 (2018).

81. Horowitz, M. C., Fretz, J. A. \& Lorenzo, J. A. How B cells influence bone biology in health and disease. Bone 47, 472-479 (2010).

82. Yonou, H. et al. Osteoprotegerin/osteoclastogenesis inhibitory factor decreases human prostate cancer burden in human adult bone implanted into nonobese diabetic/severe combined immunodeficient mice. Cancer Res. 63, 2096-2102 (2003).

83. Catalano, A. et al. Pain in osteoporosis: from pathophysiology to therapeutic approach. Drugs aging 34, 755-765 (2017).

84. Zuo, F. et al. Intrastriatal transplantation of human neural stem cells restores the impaired subventricular zone in Parkinsonian mice. Stem Cells. https://doi.org/ 10.1002/stem.2616 (2017).

85. Tatsumi, S. et al. Targeted ablation of osteocytes induces osteoporosis with defective mechanotransduction. Cell Metab. 5, 464-475 (2007).

86. Glatt, V., Evans, C. H. \& Tetsworth, K. A concert between biology and biomechanics: the influence of the mechanical environment on bone healing. Front. Physiol. 7, 678 (2016).

87. Plotkin, L. I. \& Bellido, T. Osteocytic signalling pathways as therapeutic targets for bone fragility. Nat. Rev. Endocrinol. 12, 593-605 (2016).

88. Han, M. K. L. \& de Rooij, J. Converging and unique mechanisms of mechanotransduction at adhesion sites. Trends Cell Biol. 26, 612-623 (2016).

89. Sikavitsas, V. I., Temenoff, J. S. \& Mikos, A. G. Biomaterials and bone mechanotransduction. Biomaterials 22, 2581-2593 (2001).

90. Xiao, Z. S. \& Quarles, L. D. Role of the polycytin-primary cilia complex in bone development and mechanosensing. Ann. New Y. Acad. Sci. 1192, 410-421 (2010).

91. Tu, X. et al. Osteocytes mediate the anabolic actions of canonical Wnt/betacatenin signaling in bone. Proc. Natl Acad. Sci. USA 112, E478-E486 (2015).

92. Nguyen, A. M. \& Jacobs, C. R. Emerging role of primary cilia as mechanosensors in osteocytes. Bone 54, 196-204 (2013).

93. Yavropoulou, M. P. \& Yovos, J. G. The molecular basis of bone mechanotransduction. J. Musculoskelet. Neuron. Interact. 16, 221-236 (2016).

94. Ranade, S. S., Syeda, R. \& Patapoutian, A. Mechanically activated ion channels. Neuron 87, 1162-1179 (2015).

95. Lewis, K. J. et al. Osteocyte calcium signals encode strain magnitude and loading frequency in vivo. Proc. Natl Acad. Sci. USA 114, 11775-11780 (2017).

96. $\mathrm{Xu}, \mathrm{H}$. et al. Connexin 43 channels are essential for normal bone structure and osteocyte viability. J. Bone Miner. Res. 30, 436-448 (2015).

97. Plotkin, L. I., Speacht, T. L. \& Donahue, H. J. Cx43 and mechanotransduction in bone. Curr. Osteoporos. Rep. 13, 67-72 (2015).

98. Lynch, M. E. \& Fischbach, C. Biomechanical forces in the skeleton and their relevance to bone metastasis: biology and engineering considerations. Adv. Drug Deliv. Rev. 79-80, 119-134 (2014).

99. Fedorchak, G. R., Kaminski, A. \& Lammerding, J. Cellular mechanosensing: getting to the nucleus of it all. Prog. Biophys. Mol. Biol. 115, 76-92 (2014).

100. Kim, C. H., You, L., Yellowley, C. E. \& Jacobs, C. R. Oscillatory fluid flow-induced shear stress decreases osteoclastogenesis through RANKL and OPG signaling. Bone 39, 1043-1047 (2006).

101. Temiyasathit, S. \& Jacobs, C. R. Osteocyte primary cilium and its role in bone mechanotransduction. Ann. New Y. Acad. Sci. 1192, 422-428 (2010).

102. Goggin, P. M., Zygalakis, K. C., Oreffo, R. O. \& Schneider, P. High-resolution 3D imaging of osteocytes and computational modelling in mechanobiology: insights on bone development, ageing, health and disease. Eur. Cells Mater. 31, 264-295 (2016).

103. Devlin, M. J. \& Rosen, C. J. The bone-fat interface: basic and clinical implications of marrow adiposityThe Lancet. Diab. Endocrinol. 3, 141-147 (2015).

104. Li, J., Liu, X., Zuo, B. \& Zhang, L. The role of bone marrow microenvironment in governing the balance between osteoblastogenesis and adipogenesis. Aging Dis. 7, 514-525 (2016)

105. Manolagas, S. C. The quest for osteoporosis mechanisms and rational therapies: how far we've come, how much further we need to go. J. Bone Miner. Res.: 33, 371-385 (2018).

106. Goodman, C. A., Hornberger, T. A. \& Robling, A. G. Bone and skeletal muscle: key players in mechanotransduction and potential overlapping mechanisms. Bone 80, 24-36 (2015).

107. Boyce, B. F., Xiu, Y., Li, J., Xing, L. \& Yao, Z. NF-kappaB-mediated regulation of osteoclastogenesis. Endocrinol. Metab. 30, 35-44 (2015).

108. Tarapore, R. S. et al. NF-kappaB has a direct role in inhibiting Bmp- and Wntinduced matrix protein expression. J. Bone Miner. Res. 31, 52-64 (2016).

109. Thompson, W. R., Rubin, C. T. \& Rubin, J. Mechanical regulation of signaling pathways in bone. Gene 503, 179-193 (2012)
110. Aguirre, J. I. et al. A novel ligand-independent function of the estrogen receptor is essential for osteocyte and osteoblast mechanotransduction. J. Biol. Chem. 282, 25501-25508 (2007).

111. Srinivasan, S., Gross, T. S. \& Bain, S. D. Bone mechanotransduction may require augmentation in order to strengthen the senescent skeleton. Ageing Res. Rev. 11, 353-360 (2012).

112. Devlin, M. J. Estrogen, exercise, and the skeleton. Evolut. Anthropol. 20, 54-61 (2011).

113. Loi, F. et al. Inflammation, fracture and bone repair. Bone 86, 119-130 (2016).

114. Lin, T. H. et al. NF-kappaB as a therapeutic target in inflammatory-associated bone diseases. Adv. protein Chem. Struct. Biol. 107, 117-154 (2017).

115. Salles, M. B. et al. Evaluating nuclear factor NF-kappaB activation following bone trauma: a pilot study in a Wistar rats model. PLoS One 10, e0140630 (2015).

116. Liu, T., Zhang, L., Joo, D. \& Sun, S. C. NF-kappaB signaling in inflammation. Signal Transduct.Target. Ther. 2, https://doi.org/10.1038/sigtrans.2017.23 (2017).

117. Kapoor, M., Martel-Pelletier, J., Lajeunesse, D., Pelletier, J. P. \& Fahmi, H. Role of proinflammatory cytokines in the pathophysiology of osteoarthritis. Nat. Rev. Rheumatol. 7, 33-42 (2011).

118. Long, P., Liu, F., Piesco, N. P., Kapur, R. \& Agarwal, S. Signaling by mechanical strain involves transcriptional regulation of proinflammatory genes in human periodontal ligament cells in vitro. Bone 30, 547-552 (2002)

119. Agarwal, S. et al. A central role for the nuclear factor-kappaB pathway in antiinflammatory and proinflammatory actions of mechanical strain. FASEB J. 17, 899-901 (2003).

120. Novack, D. V. Role of NF-kappaB in the skeleton. Cell Res. 21, 169-182 (2011).

121. Yu, H. S., Kim, J. J., Kim, H. W., Lewis, M. P. \& Wall, I. Impact of mechanical stretch on the cell behaviors of bone and surrounding tissues. J. Tissue Eng. 7, 2041731415618342 (2016).

122. Pires, B. R. B., Silva, R., Ferreira, G. M. \& Abdelhay, E. NF-kappaB: two sides of the same coin. Genes 9, https://doi.org/10.3390/genes9010024 (2018).

123. Wang, L. et al. Involvement of p38MAPK/NF-kappaB signaling pathways in osteoblasts differentiation in response to mechanical stretch. Ann. Biomed. Eng. 40, 1884-1894 (2012).

124. Wang, L. et al. Involvement of BMPs/Smad signaling pathway in mechanical response in osteoblasts. Cell. Physiol. Biochem.: Int. J. Exp. Cell Physiol., Biochem. Pharmacol. 26, 1093-1102 (2010).

125. Long, P., Hu, J., Piesco, N., Buckley, M. \& Agarwal, S. Low magnitude of tensile strain inhibits IL-1 beta-dependent induction of pro-inflammatory cytokines and induces synthesis of IL-10 in human periodontal ligament cells in vitro. J. Dent. Res. 80, 1416-1420 (2001)

126. Sauerschnig, M. et al. Effect of COX-2 inhibition on tendon-to-bone healing and PGE2 concentration after anterior cruciate ligament reconstruction. Eur. J. Med. Res. 23, 1 (2018).

127. Thorsen, K., Kristoffersson, A. O., Lerner, U. H. \& Lorentzon, R. P. In situ microdialysis in bone tissue. Stimulation of prostaglandin E2 release by weightbearing mechanical loading. J. Clin. Investig. 98, 2446-2449 (1996).

128. Cheung, W. H., Miclau, T., Chow, S. K., Yang, F. F. \& Alt, V. Fracture healing in osteoporotic bone. Injury 47(Suppl. 2), S21-S26 (2016).

129. Chow, S. K. et al. Mechanical stimulation enhanced estrogen receptor expression and callus formation in diaphyseal long bone fracture healing in ovariectomy-induced osteoporotic rats. Osteoporos. Int. 27, 2989-3000 (2016).

130. Thomas, M. \& Puleo, D. Infection, inflammation, and bone regeneration: a paradoxical relationship. J. Dent. Res. 90, 1052-1061 (2011).

131. Peichl, P., Holzer, L. A., Maier, R. \& Holzer, G. Parathyroid hormone 1-84 accelerates fracture-healing in pubic bones of elderly osteoporotic women. J. Bone Jt. Surg. Am. Vol. 93, 1583-1587 (2011).

132. Grundnes, O. \& Reikeras, O. The role of hematoma and periosteal sealing for fracture healing in rats. Acta Orthop. Scand. 64, 47-49 (1993).

133. Yuasa, M. et al. Fibrinolysis is essential for fracture repair and prevention of heterotopic ossification. J. Clin. Investig. 125, 3723 (2015).

134. Dohan Ehrenfest, D. M. et al. Classification of platelet concentrates (Platelet-Rich Plasma-PRP, Platelet-Rich Fibrin-PRF) for topical and infiltrative use in orthopedic and sports medicine: current consensus, clinical implications and perspectives. Muscles Ligaments Tendons J. 4, 3-9 (2014).

135. Xie, $\mathrm{H}$. et al. PDGF-BB secreted by preosteoclasts induces angiogenesis during coupling with osteogenesis. Nat. Med. 20, 1270-1278 (2014).

136. Wagatsuma, A. Effect of aging on expression of angiogenesis-related factors in mouse skeletal muscle. Exp. Gerontol. 41, 49-54 (2006).

137. Kallala, R. et al. In vitro and in vivo effects of antibiotics on bone cell metabolism and fracture healing. Expert Opin. Drug Saf. 11, 15-32 (2012).

138. Antoci, V. Jr., Adams, C. S., Hickok, N. J., Shapiro, I. M. \& Parvizi, J. Antibiotics for local delivery systems cause skeletal cell toxicity in vitro. Clin. Orthop. Relat. Res. 462, 200-206 (2007). 
139. Cope, A. P. et al. Chronic tumor necrosis factor alters $\mathrm{T}$ cell responses by attenuating T cell receptor signaling. J. Exp. Med. 185, 1573-1584 (1997),

140. Chopin, F. et al. Long-term effects of infliximab on bone and cartilage turnover markers in patients with rheumatoid arthritis. Ann. Rheum. Dis. 67, 353-357 (2008).

141. Marotte, H. et al. A 1-year case-control study in patients with rheumatoid arthritis indicates prevention of loss of bone mineral density in both responders and nonresponders to infliximab. Arthritis Res. Ther. 9, R61 (2007).

142. Roggia, C. et al. Up-regulation of TNF-producing T cells in the bone marrow: a key mechanism by which estrogen deficiency induces bone loss in vivo. Proc. Natl Acad. Sci. USA 98, 13960-13965 (2001).

143. Kimble, R. B. et al. Simultaneous block of interleukin-1 and tumor necrosis factor is required to completely prevent bone loss in the early postovariectomy period. Endocrinology 136, 3054-3061 (1995).

144. Gao, Y. et al. Estrogen prevents bone loss through transforming growth factor $\beta$ signaling in T cells. Proc. Natl Acad. Sci. USA 101, 16618-16623 (2004).

145. Scherrer, C. B., Mannion, A. F., Kyburz, D. \& Vogt, M. \& Kramers-de Quervain, I. A. Infection risk after orthopedic surgery in patients with inflammatory rheumatic diseases treated with immunosuppressive drugs.Arthritis Care Res. 65, 2032-2040 (2013).

146. Hlaing, T. T. \& Compston, J. E. Biochemical markers of bone turnover - uses and limitations. Ann. Clin. Biochem. 51, 189-202 (2014).

147. Drake, M. T., Clarke, B. L. \& Khosla, S. Bisphosphonates: mechanism of action and role in clinical practice. Mayo Clin. Proc. 83, 1032-1045 (2008).

148. Dirschl, D. R. \& Rustom, H. Practice patterns and performance in U.S. fracture liaison programs: an analysis of $>32,000$ patients from the own the bone program. J. Bone Jt. Surg. Am. Vol. 100, 680-685 (2018).

149. Hauser, M., Siegrist, M., Keller, I. \& Hofstetter, W. Healing of fractures in osteoporotic bones in mice treated with bisphosphonates-a transcriptome analysis. Bone 112, 107-119 (2018).

150. Zaheer, S., LeBoff, M. \& Lewiecki, E. M. Denosumab for the treatment of osteoporosis. Expert Opin. Drug Metab. Toxicol. 11, 461-470 (2015).

151. Bone, H. G. et al. 10 years of denosumab treatment in postmenopausal women with osteoporosis: results from the phase 3 randomised FREEDOM trial and open-label extension.The Lancet. Diabetes Endocrinol. 5, 513-523 (2017).

152. Silverman, S. L. \& Azria, M. The analgesic role of calcitonin following osteoporotic fracture. Osteoporos. Int. 13, 858-867 (2002).

153. Liu, Y. et al. Hexapeptide-conjugated calcitonin for targeted therapy of osteoporosis. J. Control. Release. 304, 39-50 (2019).

154. Ren, L. \& Wang, W. Effect of risedronate on femoral periprosthetic bone loss following total hip replacement: a systematic review and meta-analysis. Medicine 97, e0379 (2018).

155. Redlich, K. et al. Repair of local bone erosions and reversal of systemic bone loss upon therapy with anti-tumor necrosis factor in combination with osteoprotegerin or parathyroid hormone in tumor necrosis factor-mediated arthritis. Am. J. Pathol. 164, 543-555 (2004).

156. Thompson, W. R. et al. Osteocyte specific responses to soluble and mechanical stimuli in a stem cell derived culture model. Sci. Rep. 5, 11049 (2015).

157. Cianferotti, L., D'Asta, F. \& Brandi, M. L. A review on strontium ranelate long-term antifracture efficacy in the treatment of postmenopausal osteoporosis. Ther. Adv. Musculoskelet. Dis. 5, 127-139 (2013).

158. Iolascon, G. et al. Bone quality and bone strength: benefits of the bone-forming approach. Clin. Cases Miner. Bone Metab. 11, 20-24 (2014).

159. Langdahl, B. L. et al. Romosozumab (sclerostin monoclonal antibody) versus teriparatide in postmenopausal women with osteoporosis transitioning from oral bisphosphonate therapy: a randomised, open-label, phase 3 trial. Lancet 390, 1585-1594 (2017).

160. MacFarlane, E. G., Haupt, J., Dietz, H. C. \& Shore, E. M. TGF-beta family signaling in connective tissue and skeletal diseases. Cold Spring Harbor Perspect. Biol. 9, https://doi.org/10.1101/cshperspect.a022269 (2017).

161. Rys, J. P., Monteiro, D. A. \& Alliston, T. Mechanobiology of TGFbeta signaling in the skeleton. Matrix Biol.: J. Int. Soc. Matrix Biol. 52-54, 413-425 (2016).

162. Li, M., Liu, X., Liu, X. \& Ge, B. Calcium phosphate cement with BMP-2-loaded gelatin microspheres enhances bone healing in osteoporosis: a pilot study. Clin. Orthop. Relat. Res. 468, 1978-1985 (2010).

163. $\mathrm{Hu}, \mathrm{M}$. H. et al. Polymethylmethacrylate augmentation of the pedicle screw: the cement distribution in the vertebral body. Eur. Spine J. 20, 1281-1288 (2011).

164. Bettencourt, A. \& Almeida, A. J. Poly(methyl methacrylate) particulate carriers in drug delivery. J. Microencapsul. 29, 353-367 (2012).

165. Webb, J. C. \& Spencer, R. F. The role of polymethylmethacrylate bone cement in modern orthopaedic surgery. J. bone Jt. Surg. Br. Vol. 89, 851-857 (2007).

166. Arora, M., Chan, E. K., Gupta, S. \& Diwan, A. D. Polymethylmethacrylate bone cements and additives: a review of the literature. World J. Orthop. 4, 67-74 (2013).

167. Watson, J. T. \& Nicolaou, D. A. Orthobiologics in the augmentation of osteoporotic fractures. Curr. Osteoporos. Rep. 13, 22-29 (2015).
168. Schumaier, A. \& Grawe, B. Proximal humerus fractures: evaluation and management in the elderly patient. Geriatr. Orthop. Surg. Rehabilit. 9, 2151458517750516 (2018).

169. Chan, M. E., Uzer, G. \& Rubin, C. T. The potential benefits and inherent risks of vibration as a non-drug therapy for the prevention and treatment of osteoporosis. Curr. Osteoporos. Rep. 11, 36-44 (2013).

170. Nagaraja, M. P. \& Jo, H. The role of mechanical stimulation in recovery of bone loss-high versus low magnitude and frequency of force. Life 4, 117-130 (2014).

171. Griffin, X. L., Parsons, N., Costa, M. L. \& Metcalfe, D. Ultrasound and shockwave therapy for acute fractures in adults. Cochrane Database Syst. Rev. Cd008579, https://doi.org/10.1002/14651858.CD008579.pub3 (2014).

172. Miller, P. D. The history of bone densitometry. Bone 104, 4-6 (2017)

173. Seeman, E. Pathogenesis of bone fragility in women and men. Lancet 359, 1841-1850 (2002).

174. de Bakker, C. M. J., Tseng, W. J., Li, Y., Zhao, H. \& Liu, X. S. Clinical evaluation of bone strength and fracture risk. Curr. Osteoporos. Rep. 15, 32-42 (2017).

175. Silva, B. C. et al. Trabecular bone score (TBS) - a novel method to evaluate bone microarchitectural texture in patients with primary hyperparathyroidism. J. Clin. Endocrinol. Metab. 98, 1963-1970 (2013).

176. Harvey, N. C. et al. Trabecular bone score (TBS) as a new complementary approach for osteoporosis evaluation in clinical practice. Bone 78, 216-224 (2015).

177. Shevroja, E. et al. Use of trabecular bone score (TBS) as a complementary approach to dual-energy X-ray absorptiometry (DXA) for fracture risk assessment in clinical practice. J. Clin. Densitom. 20, 334-345 (2017).

178. Iki, M. et al. Trabecular bone score may improve FRAX(R) prediction accuracy for major osteoporotic fractures in elderly Japanese men: the Fujiwara-kyo Osteoporosis Risk in Men (FORMEN) Cohort Study. Osteoporos. Int. 26, 1841-1848 (2015).

179. Brandi, M. L. Microarchitecture, the key to bone quality. Rheumatology $\mathbf{4 8}$ (Suppl. 4), iv3-iv8 (2009)

180. Eckert, J. A., Jaeger, S., Klotz, M. C., Schwarze, M. \& Bitsch, R. G. Can intraoperative measurement of bone quality help in decision making for cementless unicompartmental knee arthroplasty? Knee 25, 609-616 (2018).

181. Seebeck, J. et al. Effect of cortical thickness and cancellous bone density on the holding strength of internal fixator screws. J. Orthop. Res. 22, 1237-1242 (2004).

182. Shea, T. M. et al. Designs and techniques that improve the pullout strength of pedicle screws in osteoporotic vertebrae: current status. BioMed. Res. Int. 2014, 748393 (2014)

183. Wang, T., Boone, C., Behn, A. W., Ledesma, J. B. \& Bishop, J. A. Cancellous screws are biomechanically superior to cortical screws in metaphyseal bone. Orthopedics 39, e828-e832 (2016).

184. Cornell, C. N. Internal fracture fixation in patients with osteoporosis. J. Am. Acad. Orthop. Surg. 11, 109-119 (2003).

185. Ab-Lazid, R., Perilli, E., Ryan, M. K., Costi, J. J. \& Reynolds, K. J. Does cancellous screw insertion torque depend on bone mineral density and/or microarchitecture? J. Biomech. 47, 347-353 (2014).

186. Karim, L. \& Vashishth, D. Role of trabecular microarchitecture in the formation, accumulation, and morphology of microdamage in human cancellous bone. J. Orthop. Res. 29, 1739-1744 (2011).

187. Greiwe, R. M. \& Archdeacon, M. T. Locking plate technology: current concepts. J. Knee Surg. 20, 50-55 (2007).

188. Miranda, M. A. Locking plate technology and its role in osteoporotic fractures. Injury 38(Suppl. 3), S35-S39 (2007).

189. Kralinger, F. et al. The influence of local bone density on the outcome of one hundred and fifty proximal humeral fractures treated with a locking plate. J. Bone Jt. Surg. Am. Vol. 96, 1026-1032 (2014).

190. Johanson, N. A., Litrenta, J., Zampini, J. M., Kleinbart, F. \& Goldman, H. M. Surgical treatment options in patients with impaired bone quality. Clin. Orthop. Relat. Res. 469, 2237-2247 (2011).

191. Ito, K., Hungerbuhler, R., Wahl, D. \& Grass, R. Improved intramedullary nail interlocking in osteoporotic bone. J. Orthop. Trauma 15, 192-196 (2001).

192. McKee, M. D. et al. A multicenter, prospective, randomized, controlled trial of open reduction-internal fixation versus total elbow arthroplasty for displaced intra-articular distal humeral fractures in elderly patients. J. Shoulder Elb. Surg. 18, 3-12 (2009).

193. Boraiah, S., Ragsdale, M., Achor, T., Zelicof, S. \& Asprinio, D. E. Open reduction internal fixation and primary total hip arthroplasty of selected acetabular fractures. J. Orthop. Trauma 23, 243-248 (2009).

194. Goldhahn, J., Suhm, N., Goldhahn, S., Blauth, M. \& Hanson, B. Influence of osteoporosis on fracture fixation-a systematic literature review. Osteoporos. Int. 19, 761-772 (2008) 
195. Seebeck, J., Goldhahn, J., Morlock, M. M. \& Schneider, E. Mechanical behavior of screws in normal and osteoporotic bone. Osteoporos. Int. 16(Suppl. 2), S107-S111 (2005).

196. McAndrew, C. M. et al. Local bone quality measurements correlates with maximum screw torque at the femoral diaphysis. Clin. Biomech. 52, 95-99 (2018).

197. Parkinson, I. H. \& Fazzalari, N. L. Whole bone geometry and bone quality in distal forearm fracture. J. Orthop. Trauma 22, S59-S65 (2008).

198. Cornell, C. N. \& Ayalon, O. Evidence for success with locking plates for fragility fractures. HSS J. 7, 164-169 (2011).

199. Ricci, W. M., Tornetta, P. \& Borrelli, J. Jr. Lag screw fixation of medial malleolar fractures: a biomechanical, radiographic, and clinical comparison of unicortical partially threaded lag screws and bicortical fully threaded lag screws. J. Orthop. trauma 26, 602-606 (2012).

200. Egol, K. A., Kubiak, E. N., Fulkerson, E., Kummer, F. J. \& Koval, K. J. Biomechanics of locked plates and screws. J. Orthop. trauma 18, 488-493 (2004).

201. Babhulkar, S. Unstable trochanteric fractures: Issues and avoiding pitfalls. Injury 48, 803-818 (2017).

202. Oheim, R., Schinke, T., Amling, M. \& Pogoda, P. Can we induce osteoporosis in animals comparable to the human situation? Injury 47(Suppl. 1), S3-S9 (2016).

203. Sproul, R. C., lyengar, J. J., Devcic, Z. \& Feeley, B. T. A systematic review of locking plate fixation of proximal humerus fractures. Injury 42, 408-413 (2011).
204. Mellibovsky, L. et al. Bone tissue properties measurement by reference point indentation in glucocorticoid-induced osteoporosis. J. Bone Miner. Res. 30, 1651-1656 (2015).

205. Sanchez-Riera, L. et al. Osteoporosis and fragility fractures. Best Pract. Res. Clin. Rheumatol. 24, 793-810 (2010).

(i) Open Access This article is licensed under a Creative Commons Attribution 4.0 International License, which permits use, sharing, adaptation, distribution and reproduction in any medium or format, as long as you give appropriate credit to the original author(s) and the source, provide a link to the Creative Commons license, and indicate if changes were made. The images or other third party material in this article are included in the article's Creative Commons license, unless indicated otherwise in a credit line to the material. If material is not included in the article's Creative Commons license and your intended use is not permitted by statutory regulation or exceeds the permitted use, you will need to obtain permission directly from the copyright holder. To view a copy of this license, visit http://creativecommons. org/licenses/by/4.0/.

(c) The Author(s) 2019 